\title{
Surplus from and storage of electricity generated by intermittent sources $^{\star}$
}

\author{
Friedrich Wagner ${ }^{\mathrm{a}}$ \\ Max-Planck-Institut für Plasmaphysik, Branch Greifswald, Wendelsteinstraße 1, 17491 Greifswald, Germany
}

Received: 17 September 2016 / Revised: 12 November 2016

Published online: 27 December 2016

(c) The Author(s) 2016. This article is published with open access at Springerlink.com

\begin{abstract}
Data from the German electricity system for the years 2010, 2012, 2013, and 2015 are used and scaled up to a $100 \%$ supply by intermittent renewable energy sources (iRES). In the average, $330 \mathrm{GW}$ wind and PV power are required to meet this $100 \%$ target. A back-up system is necessary with the power of $89 \%$ of peak load. Surplus electricity accrues at high power levels. Curtailing surplus power to a large extent is found to be uneconomic. Demand-side management will suffer from the strong day-to-day variation of available surplus energy. A day storage is ineffective because of the day-night correlation of surplus power during winter. A seasonal storage loses its character when transformation losses are considered because it can contribute only after periods with excessive surplus production. The option of an oversized iRES system to feed the storage is also not effective because, in this case, energy can be taken directly from the large iRES supply, making storage superfluous. The capacities to be installed stress the difficulty to base heat supply and mobility also on iRES generated electricity in the future. As the German energy transition replaces one $\mathrm{CO}_{2}$-free electricity supply system by another one, no major reduction in $\mathrm{CO}_{2}$ emission can be expected till 2022, when the last nuclear reactor will be switched off. By 2022, an extremely oversized power supply system has to be created, which can be expected to continue running down spot-market electricity prices. The continuation of the economic response - to replace expensive gas fuel by cheap lignite- causes an overall increase in $\mathrm{CO}_{2}$ emission. The German GHG emission targets for 2020 and beyond are therefore in jeopardy.
\end{abstract}

\section{Introduction}

The supply of electricity by the intermittent sources, wind and photo voltaic (PV) power, depends on weather conditions. In order to understand the benefits and problems of intermittent electricity production, the variability of weather conditions has to be analysed first. The weather analysis presented here is not based on meteorological data per se, rather it is carried out using derived and more specific data from the electricity supply system itself. This is done, in this paper, with data collected for Germany. This country is the best target for such a study because the use of intermittent renewable energies (iRES) is the most advanced one in Europe and there is the strong political and societal will to replace the present electricity supply situation regulated by demand by one driven by supply. Input data are the load of Germany representing the consumption and the iRES data of wind and PV power. These data are publicly available with $15 \mathrm{~min}$ resolution and they have been used in previous studies $[1-4]^{1}$. The study presented here is mostly based on data from 2012 but also uses data from 2010 to 2015 to explore the annual variability ${ }^{2}$.

\section{Analysis of intermittent electricity production}

The frame of the implicit weather analysis presented here is the so-called 100\%, optimal-mix case [1]. The iRES power is extrapolated from the present state, e.g. the data of 2012, to the $100 \%$ case, where the iRES system with wind

\footnotetext{
* Contribution to the Focus Point on "The Transition to Sustainable Energy Systems" edited by J. Ongena.

a e-mail: fritz.wagner@ipp.mpg.de

1 We acknowledge the use of data from https://www.entsoe.eu/data/data-portal/country-packages/; www.50hertz.com/; www.tennet.eu/de/home.html; www.amprion.net/ and https://www.transnetbw.de/.

${ }^{2} 2014$ is analysed along similar objectives in H.-W. Sinn, Buffering Volatility: A Study on the Limits of Germany's Energy Revolution, CESifo Working Paper \# 5950, June 2016.
} 


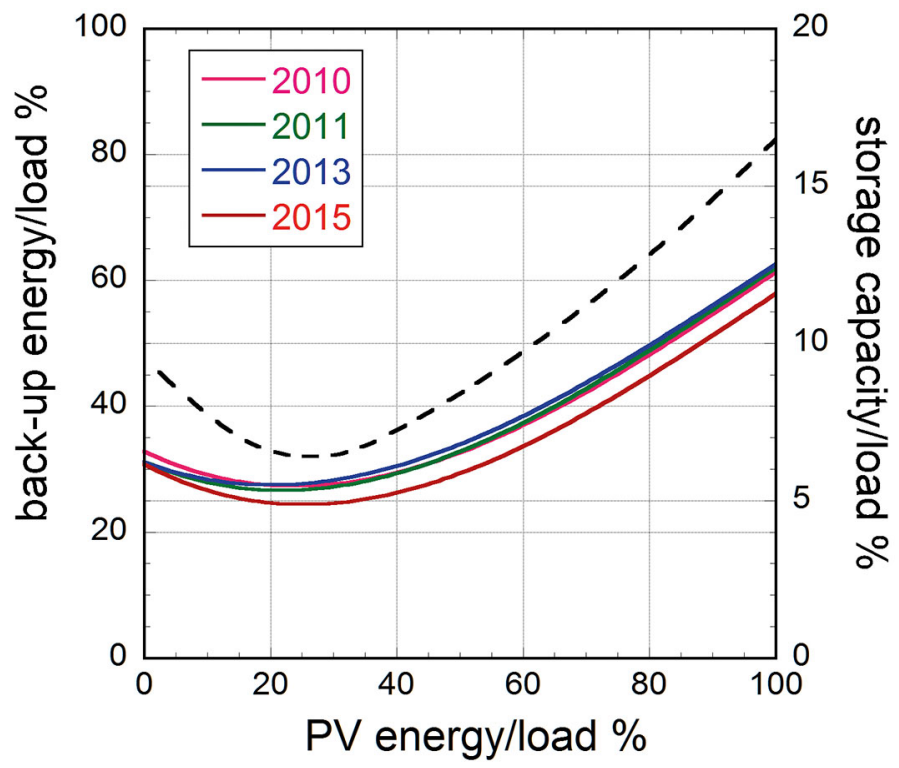

Fig. 1. The annual back-up energy (left ordinate) and the storage capacity (right ordinate) is plotted against the annually produced PV energy. All parameters are normalised by the annual reduced load. Solid curves are the back-up energy for the following years: pink, 2010; green 2012; blue 2013; red 2015. The dashed curve represents the case when storage replaces the back-up system based on 2012 data (see sect. 4). The minimum defines the PV contribution for the optimal mix.

and PV power generates as much electricity per year as is consumed. Hydropower is assumed constant at the level of $20 \mathrm{TWh}$ for Germany. Biogas is not considered. In the future with the expectation that $100 \%$ of electricity is produced by wind and PV power, the need to make aviation and heavy transportation also $\mathrm{CO}_{2}$-free will reserve the nationally produced biomass preferentially for this purpose. In 2012 nearly 40 TWh of electricity were obtained from bio-gas ${ }^{3}$. Nuclear energy as well as electricity import and export are also not considered here. To begin with, we present the ideal case without any losses. Because of the intermittent nature of iRES power a back-up system is needed as a supplement during unfavourable weather conditions. Eventually, the back-up should be replaced by a storage system. When we analyse the conditions for storage operation we also include transformation losses.

The optimal mix between wind and PV power is defined according to the minimal back-up energy needed during the year when the weather conditions do not allow iRES to fully meet the demand. Figure 1 shows the dependence of the back-up versus the annual PV energy for the four years considered here (solid curves). Both quantities are normalised to the annual load. The shallow minimum around a PV contribution of 20-25\%, which is rather invariable from year to year, defines the optimal share. The dashed curve shows the relation of normalised storage capacity versus PV energy. Also in this case, which differs because also charging processes play a role, a minimum develops at about the same PV energy share. The splitting between onshore and offshore wind is arbitrarily set to $2 / 3$ and $1 / 3$ [1].

The annual net electricity consumption in Germany varies somewhat from year to year. We assume that it will be 520 TWh in the future ${ }^{4}$ so that wind and PV installations will contribute with 500 TWh in the $100 \%$ case; the rest is provided by hydroelectricity at the assumed constant level. We define the reduced load by scaling the actual load curve of the year under consideration such that the integral over the year adds up to the annual reduced load of 500 TWh. This energy is the target for the annual electricity generation by wind and PV power. A fixed target energy allows a better comparison of the different years. The difference between the variation of the load and the reduced load is small and does not affect the results.

The transition from the present situation to the future one is shown in fig. 2. The bar chart on the left side shows the 2012 electricity production added up from the different sources ${ }^{5}$. $56 \%$ of the consumption is based on fossil fuel causing $\mathrm{CO}_{2}$ release; $11.9 \%$ is contributed by wind (largely onshore in 2012) and PV power. The right column adds up the energy contributions of wind and PV power along with the contribution from a back-up system - or, alternatively, at a later stage, the work of a storage system. In the $100 \%$ case, wind and PV capacities produce 500 TWh. Based on the data of 2012 and under the optimal mix conditions, onshore wind contributes with 271 TWh, offshore wind

\footnotetext{
3 2015: 44TWh electricity by bio-gas. See, e.g., http://de.statista.com/statistik/daten/studie/169145/umfrage/ stromproduktion-durch-biomasse-in-deutschland-seit-2000/.

4 The net electricity consumptions were the following. 2010: 541 TWh; 2012: 534 TWh; 2013: 536 TWh; 2015: 531 TWh. Source: statista.com.

${ }^{5}$ http://www.ag-energiebilanzen.de/index .php?article_id=20\&archiv=13\&year=2013.
} 


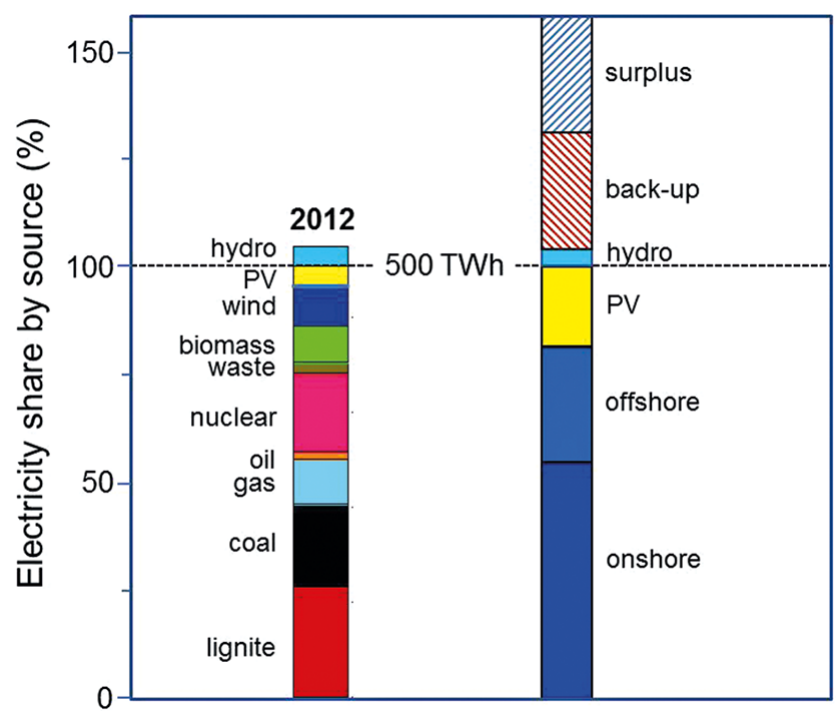

Fig. 2. The left bar shows the energy contributions (in \%) of the various sources to the net annual electricity production of Germany in 2012; the right bar shows it for the 100\%, optimal mix case when only wind and PV power meet the target annual load. Shown are also the surplus and the back-up energies, which are identical for the $100 \%$ case.

with $135 \mathrm{TWh}$ and PV power with $94 \mathrm{TWh}$. However, $131 \mathrm{TWh}$ are surplus energy accruing at a power level above the actual reduced load value and therefore without direct use. In the $100 \%$ case, this energy contribution is missing at other times and has to be replaced by a back-up system delivering exactly 131 TWh. From the 500 TWh produced by wind and PV power, only $74 \%$ can be directly used.

The reduced load curve for 2012 varies between the maximum of $83 \mathrm{GW}$ and the minimum of $\sim 33 \mathrm{GW}$ and it shows the typical diurnal variation between day and night and the weekly variation between working days and weekend. The iRES power which has to be installed to gain the respective energies are $176 \mathrm{GW}$ onshore, $33 \mathrm{GW}$ offshore and $97 \mathrm{GW}$ PV power, in total $306 \mathrm{GW}$. The back-up system has to provide $73 \mathrm{GW}$, which is $12 \%$ below the peak demand [1]. At the end of 2015 , about $41 \mathrm{GW}$ of onshore, $3 \mathrm{GW}$ offshore wind and about $39 \mathrm{GW}$ of PV power had been installed in Germany $^{6}$. For the $100 \%$, optimal mix case, the onshore wind power has to be increased by a factor of 4.2 , offshore wind by a factor of 10 and PV power by a factor of 2.4. The ratio of the average power to the installed power gives the capacity factors $c f$, which were for the 2012 conditions $0.18,0.41$ and 0.1 for onshore, offshore and PV production, respectively. In this case, the totally produced energy is compared with the installed power. As long as there is no economic use of the surplus energy the $c f$ has to be defined via the directly used energy related to the installed power which is 0.13 for the total supply system. With proper use of the surplus energy, this value rises to 0.17. $c f$ of the back-up system is 0.2. All these values are fairly low and do not promise an economic use of the respective investments.

Table 1 summarises some of the major system parameters of the $100 \%$, optimal mix cases for 2010 up to 2015 . The original iRES data have been corrected for the actual installed power values at the end of the year and represent data at constant installed power. The values for full-load hours, $f l h^{7}$, and $c f$, represent the temporal variation of the wind and solar power field over Germany in an integral form. In the years considered, $f l h$ varies by 12 days. $u f$ is called utility factor [1], which is the ratio between the maximal power value in the respective data array to the actually installed power at the end of the year, which is obtained from official sources in Germany ${ }^{8}$. $u f<1$ is caused by the spatial variation of the wind and solar power field over Germany. $u f$ is calculated from the corrected original iRES power values and applied to calculate the up-scaled installed powers for the 100\%, optimal mix case. As for more power more land is required including less attractive sites, uf will have the tendency to decrease. Indeed, between 2010 and 2015, uf of onshore wind decreased by about $0.8 \%$ per year whereas the installed power increased from 27 to $41.7 \mathrm{GW}$ in this period. The consequence is that eventually more power has to be installed for the $100 \%$ case than anticipated here ${ }^{9}$. For offshore wind installations, $u f=1$ for 2010 to 2013 because the few turbines in operation were spatially rather concentrated.

\footnotetext{
${ }^{6}$ http://www.erneuerbare-energien.de/EE/Navigation/DE/Service/Erneuerbare_Energien_in_Zahlen/Zeitreihen/ zeitreihen.html.

7 Ratio of energy produced to installed power.

8 http://www.ag-energiebilanzen.de/, http://www.bmwi.de/DE/Themen/Energie/Strommarkt-der-Zukunft/zahlenfakten.html

9 The spatial spreading of the iRES sources will cause uf to decrease but also the level of intermittency to decrease. This is obvious when the equivalent data of neighbouring countries of Germany are used to jointly establish an EU-wide iRES field [3]. The standard deviations of the power gradients for the back-up or surplus power considered in this paper reflect annual variations but not yet a trend.
} 
Table 1. Characteristic data (produced electricity, installed power, system parameters calculated from the directly used energy averaged over the three generation technologies and the maximum iRES power normalised to the peak load to describe the system dynamics) for the extrapolated $100 \%$, optimal mix case for the 4 years considered in this paper. In each case, the iRES production adds up to the target annual load of 500 TWh exclusively produced by wind and PV power. (Updated 2010 wind data obtained from transparency platforms (EEX, ENTSO-E, German TSOs) have been provided by VGB Power Tech e.V.; courtesy: Th. Linnemann, G.S. Vallana.)

\begin{tabular}{|l|c|c|c|c|}
\hline & 2010 & 2012 & 2013 & 2015 \\
\hline Production Won, TWh & 264 & 271 & 270 & 258 \\
\hline Production Woff, TWh & 132 & 135 & 136 & 129 \\
\hline Production PV, TWh & 104 & 94 & 94 & 113 \\
\hline Production back-up/surplus, TWh & 136 & 131 & 137 & 122 \\
\hline Installed power Won, GW & 191 & 176 & 183 & 117 \\
\hline Installed power Woff, GW & 59 & 33 & 33 & 53 \\
\hline Installed power PV, GW & 139 & 97 & 109 & 128 \\
\hline Installed power back-up, GW & 72 & 73 & 72 & 73 \\
\hline Full-load hour $f l h, \mathrm{~h}$ & 1261 & 1206 & 1118 & 1268 \\
\hline Capacity factor $c f, \%$ & 14 & 14 & 13 & 14 \\
\hline Utilisation factor $u f, \%$ & 52 & 59 & 60 & 57 \\
\hline$p_{\text {iRES }}$ max /peak load, $\%$ & 253 & 216 & 244 & 221 \\
\hline$p_{\text {iRES }}$ min / peak load, $\%$ & 1.1 & 1.8 & 1.1 & 1.9 \\
\hline
\end{tabular}

The data vary between the different years because the weather conditions are not identical. But there is little variation of the composition of the different energy contributions, which add up to the target annual load of $500 \mathrm{TWh}$ for the 4 cases considered. The total power to be installed varies, however, between 298 (2015) and 389 GW (2010). This is quite a substantial difference. The 2010 power installations, operating under the conditions of 2015, would produce 613 TWh surpassing the $100 \%$ limit by $23 \%$. The consequence is that a strong variation of the produced iRES energy from year to year has to be expected for a given power capacity. This feature of iRES is well known from hydro-electricity, another electricity source which depends on weather conditions.

The characteristics of a system targeted at $100 \%$ and composed following the optimal mix guidelines have been discussed in refs. [1,2] for Germany, in [5,6] for France, in [7] for Italy and in [9] for the Czech Republic. Reference [4] compares the use of iRES in France and Germany. Here we analyse in more detail first the specific, weather-dependent aspects of intermittency of wind and PV power. The maximal and minimal power values normalised to the peak load values of the respective years are given in table 1 . The highest iRES power contribution in 2012 (scaled up to the $100 \%$ level!) was $180 \mathrm{GW}$, March 31st at noon time; the lowest level of $1.5 \mathrm{GW}$ was November 15 th during the night.

Figure 3 shows the two weeks with the highest and the lowest iRES contribution, respectively. Plotted are the summed-up wind and PV contributions together with those of the back-up system (brown) to meet the reduced load given as black curves. The reduced load is constructed from the course of the published load data with slightly reduced amplitudes so that the integral, the annual load, matches the target of $500 \mathrm{TWh}$. In the left case surplus energy is produced specifically during noon times thanks to PV. This effect is aggravated in summer. In the other case, the back-up system is in use throughout the week. Actually, in this period, it was in continuous operation for 12 days.

A more detailed analysis is presented for the 2012 conditions in order to identify the power levels of surplus energy and the dynamics of the back-up — or, alternatively when once available, of a storage - system. Figure 4 shows histograms of the total iRES power (left), the back-up (middle) and the surplus (right) power accruing above the associated reduced load value in course of the year. The power levels range up to $180 \mathrm{GW}$ and are sorted into $10 \mathrm{GW}$ intervals. The power range of the load from 33 to $83 \mathrm{GW}$ serves as reference and is shown as blue band. The power values below the lower band reflect the need for back-up, the values above the upper load level are part of the surplus.

Unlike the load, the power range of the back-up power starts at zero power and goes up to 73 GW. The excess power also starts at zero but has power values beyond the maximum of the load reaching up to 129 GW. The energy content of the surplus power beyond the load maximum of $83 \mathrm{GW}$ is $27 \mathrm{TWh}$, which is the high-power part of the total surplus. $27 \mathrm{TWh}$ is more than the electricity consumption of Berlin and Hamburg. However, its practical implementation requires powerful installations with the capability to handle large power peaks in the input stage. 

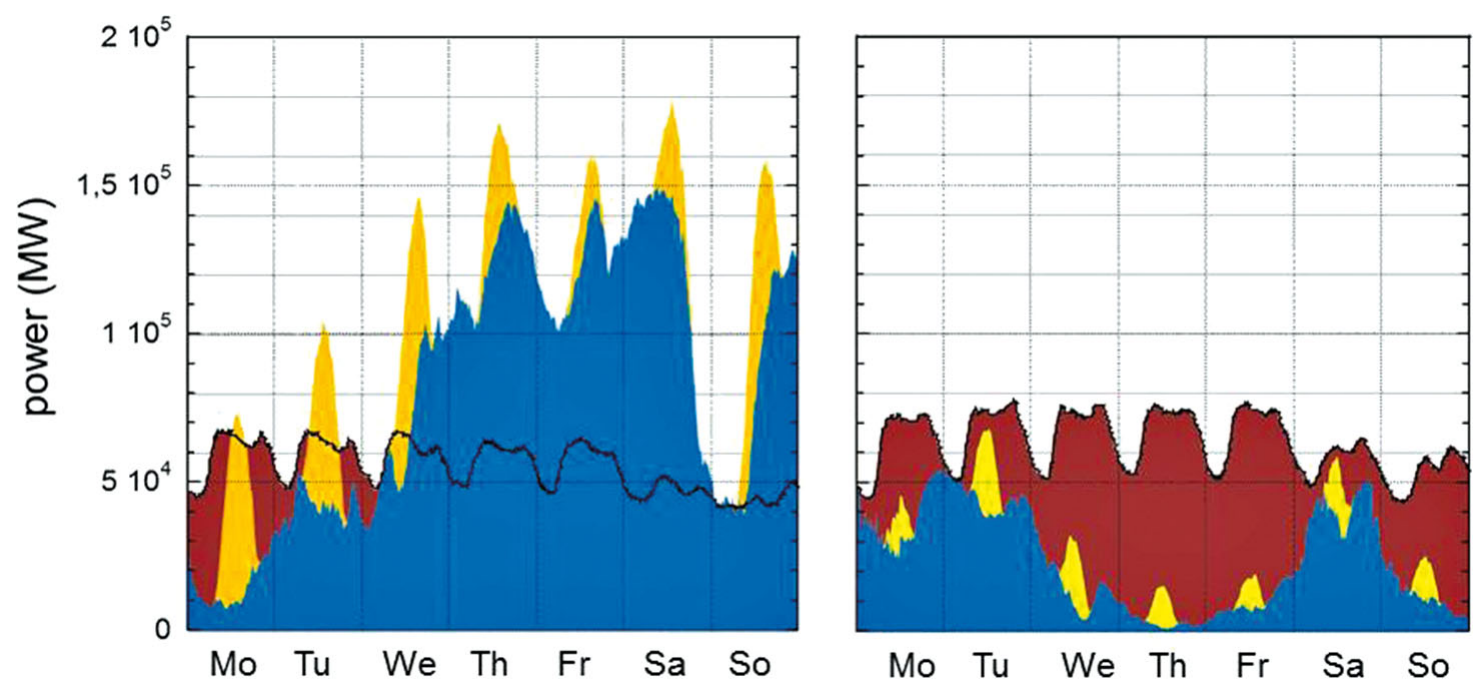

Fig. 3. For the week from 26.3. to 1.4.2012 (left) and the one from 12.to 18.11.2012 (right) the wind (blue), PV (yellow) and back-up (brown) powers are plotted versus time from Monday to the following Sunday. The reduced load (definition in the main text) is given as black curves.
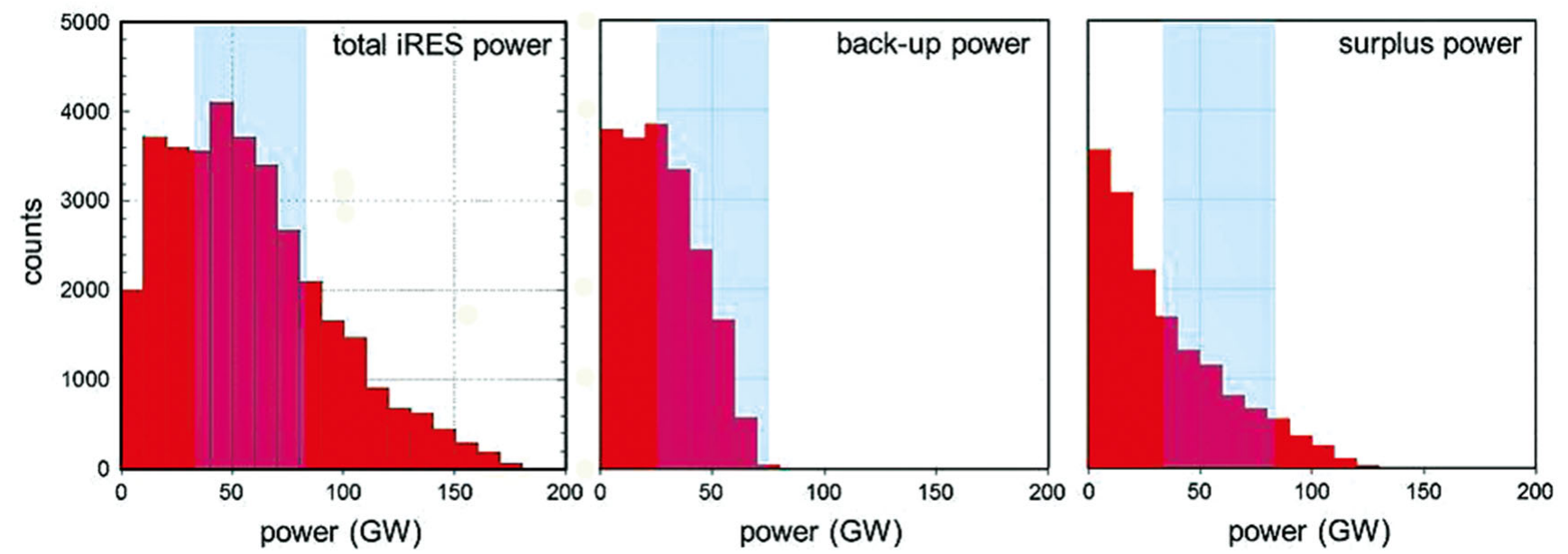

Fig. 4. Histograms of the intermittent iRES power (left, summed over the three generation technologies), the back-up (middle) and the surplus (right) power for the 100\%, optimal mix case of 2012 sorted into $10 \mathrm{GW}$ intervals. The power range of the load is shown as blue band serving as reference.

Figure 5 represents the results of the analysis for power and critical time intervals in the form of annual duration curves $^{10}$ (ADCs) for 2012. Those are shown for the iRES power generated (red curve), for the reduced load (black) and the back-up system under 100\%, optimal mix conditions (grey) along with those cases where the directly used iRES power $p_{\text {iRES }}(i)$ stays below (or is equal to) the value of the reduced load $p_{\text {rload }}(i)$ at the considered moment $i$ or is $60,40,20$, or $10 \%$ of it (blue curves), respectively. The ADCs of fig. 5 allow the following conclusions: The footprints of the curves at the $x$-axis define the time interval for which the specified conditions apply. E.g. the iRES power is less than $10 \%$ of the respective reduced load value $p_{\text {rload }}(i)$ for $171 \mathrm{~h}$ ( 7 days) and it is less than $20 \%$ for nearly a month. The $171 \mathrm{~h}$ for power values below $10 \%$ of the respective reduced load add up to $16 \mathrm{~h}$ with duration lower than $1 \mathrm{~h}$, to $98 \mathrm{~h}$ with duration between 1 and $6 \mathrm{~h}$ and to $57 \mathrm{~h}$ with duration between 6 and $12 \mathrm{~h}$. The area under the ADC curves represents the energy generated under the defined conditions (or the one needed in case of the load). From the $500 \mathrm{TWh}$ generated by iRES, $369 \mathrm{TWh}(74 \%)$ are directly used. The rest is surplus energy. $153 \mathrm{TWh}(41 \%)$ of the directly used energy accrues at a power level below or equal to the load and $216 \mathrm{TWh}(59 \%)$ with $p_{\text {iRES }}$ being larger than the respective power value of the load. These numbers highlight the large iRES power, which has to be installed to harvest the necessary energy and that it is unavoidable under these specific conditions of accepting large levels of surplus energy. The iRES energy produced during the $171 \mathrm{~h}$ at a supply level which is below $10 \%$ of the demand is $0.72 \mathrm{TWh}$; the actual demand in these periods adds up to $10 \mathrm{TWh}$.

\footnotetext{
10 In an annual duration curve the power values of generation or consumption, which are originally given as time series, are ordered in falling sequence.
} 


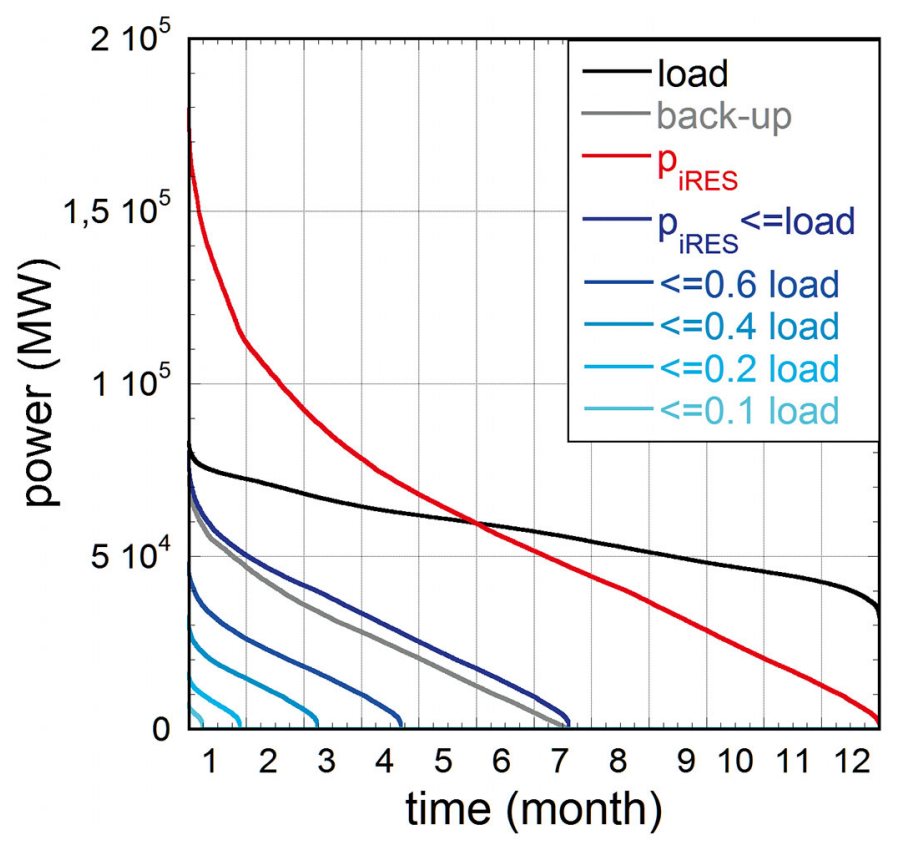

Fig. 5. Annual duration curves (ADC) of the reduced load, the iRES power and the back-up power for the $100 \%$, optimal mix case of 2012. The ADC of the iRES power is decomposed into power fractions of the respective associated reduced load values as given in the insert.
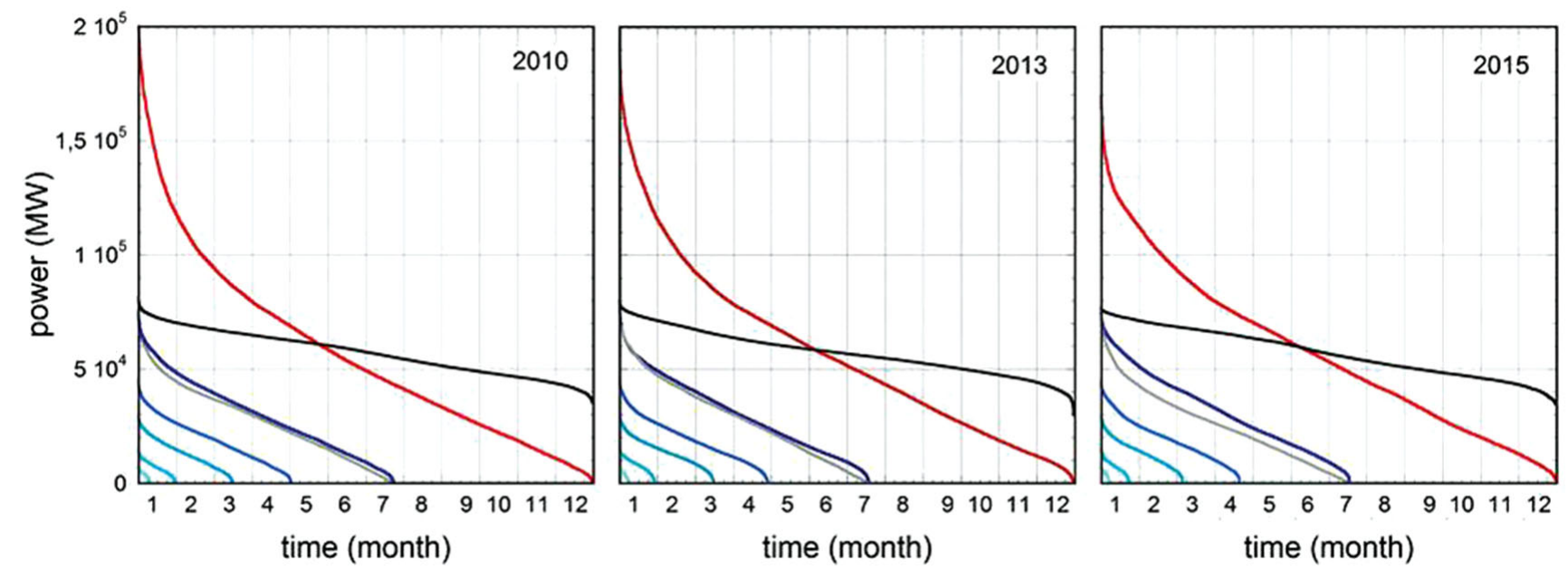

Fig. 6. Annual duration curves (ADC) of the load, the iRES power and the back-up power for the $100 \%$, optimal mix case of 2010, 2013 and 2015. The ADC of the iRES power is decomposed into power fractions of the respective load as given in the insert to fig. 5 .

Next, we look into the variation of these parameters from year to year. Figure 6 plots the annual duration curves for 2010, 2013 and 2015 in the template of fig. 5. The similarities are striking indicating a small variation of the iRES power spectrum from year to year. Specifically, the annual duration curves of load and back-up power show little variation. The peak power of the back-up system varies between $72 \mathrm{GW}$ and $73 \mathrm{GW}$ (see table 1). The iRES peak power values differ between $230 \mathrm{GW}(2012)$ and $195 \mathrm{GW}(2015)^{11}$. Also the periods with reduced iRES power are rather similar. The periods where $p_{\text {iRES }}$ is $10 \%$ or less of the respective load value last for $220 \mathrm{~h}$ in $2010,171 \mathrm{~h}$ in 2012 , $169 \mathrm{~h}$ in 2013 , and $143 \mathrm{~h}$ in 2015 . These weather dependent characteristics and their variability have to be considered in a complete system change toward an electricity supply with intermittent generation. The low-power period duration might be a sensitive parameter to characterise the level of intermittency; its steady decrease might be the result of reduced intermittency with increased and further distributed generation capacity.

11 These values allow determining the installed powers employing the $u f$-values of the different technologies. 


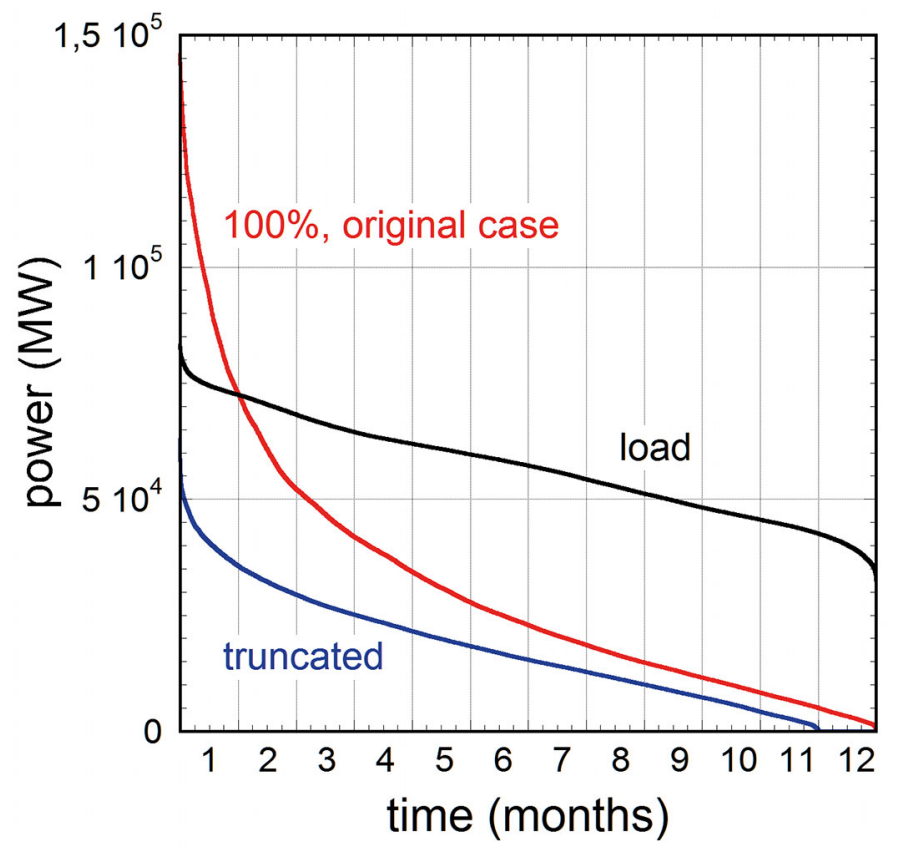

Fig. 7. Annual duration curves (ADC) for the onshore wind power of the $100 \%$, optimal mix case in 2012 (red) and for the case that only onshore wind is throttled whenever surplus power is produced. The ADC of the load is given for orientation.

\section{The use of surplus energy}

\subsection{Curtailing production}

No notable surplus electricity is produced below a share of about $25 \%$ of electricity generation by intermittent sources. In this case, the optimally mixed power of wind and PV stays with 76 GW (based on 2012) below peak load of 83 GW. When wind and PV produce $30 \%$ of the demand, the surplus energy rises to $180 \mathrm{GWh}$. The annual surplus energies generated under the 100\%, optimal mix conditions are listed in table 1 and range from 122 to 137 TWh. The surplus energy compares with the electricity consumption of Poland or Sweden indicating that it is not possible to forego what is actually of high economic value. Therefore, all concepts to overcome the surplus problem, e.g. by curtailing production, have to be weighted carefully against economic losses. Also an economy model is required to compensate owners of turbines and PV power installations taken out of operation ${ }^{12}$ if indeed the strategy of curtailing production is unavoidable. Curtailing production requires different measures when the regulation happens at the level of PV or of wind production. The alternative use of surplus - its storage and re-use in the form of electricity, e.g., to replace a $\mathrm{CO}_{2}$ generating back-up system - will be discussed further down.

Surplus is produced for $3949 \mathrm{~h}$ under 2012 conditions. There are two general possibilities to avoid surplus production by either curtailing the PV systems in periods where the wind power $p_{\mathrm{W}}(i)$ is above the reduced load $p_{\text {rload }}(i)$ at the considered moment $i$ or by curtailing wind power when PV power is above the load. For 2012 conditions PV power can be curtailed for $2895 \mathrm{~h}$ reducing the PV production from 94 to $71 \mathrm{TWh}$. In this sense, 23 TWh PV electricity, typically $20 \%$ of the total production is already covered by wind power. For $295 \mathrm{~h}$ the PV power $p_{\mathrm{PV}}(i)$ is larger than the reduced load $p_{\text {rload }}(i)$. Curtailing wind power in these periods saves only 2 TWh surplus. To achieve a major effect onshore wind has to be curtailed as is already practice today. It could be less attractive (economically and practically) to curtail offshore wind and, as we have discussed above, it does not seem to be very economic to reduce PV power.

Figure 7 shows the annual duration curves for the onshore wind contribution of the $100 \%$, optimal mix case of 2012 and compares it with the one obtained after curtailing it (blue curve). The ADC of the load is given for comparison. After truncation, the overall wind contribution drops from 271 to $149 \mathrm{TWh}$. The capacity factor of the onshore wind system drops from 0.18 to 0.08 . The back-up contribution is, of course, unchanged and the remaining surplus drops to $9.7 \mathrm{TWh}$. These numbers show how crucial onshore wind contributes to both the iRES energy directly dispatched but also to surplus electricity. For about one month in total (see fig. 7) the onshore wind system has to be turned off completely. This form of intervention succeeds in strongly reducing the surplus power production and avoids large grid power levels $(97 \mathrm{GW}$ instead of $180 \mathrm{GW})$. Nevertheless, the economic losses are substantial because the reduced onshore wind electricity is produced at a capacity factor, which is more than halved so that the wind electricity price can be expected to be more than doubled if this control scheme were to be applied.

\footnotetext{
12 At present, the investors are paid irrespective of the actual use of their systems.
} 


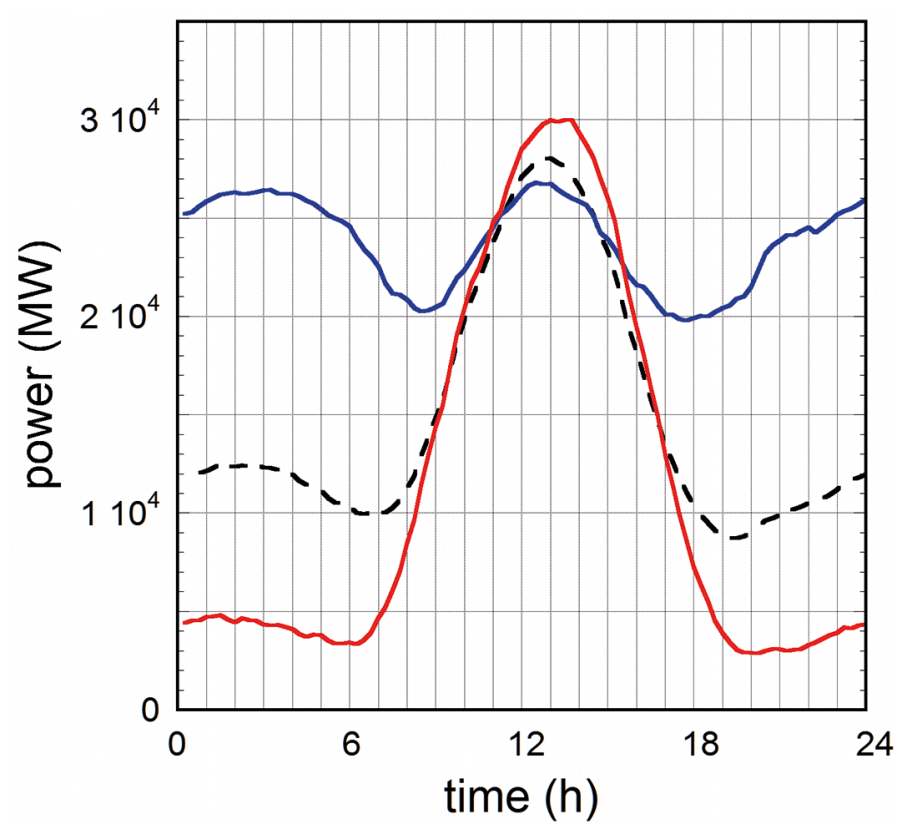

Fig. 8. Dashed curve: variation of the annually averaged surplus power for the $100 \%$, optimal mix case of 2012 during the day; red curve: during summer (averaged over June-August); blue curve: during winter (December-February).

In summary, cutting power peaks and curtailing iRES production as a means to cope with surplus production does not seem to be an economic and therefore viable strategy for reducing the overall power level when rigorously applied.

\subsection{Adaption of electricity consumption}

Demand-side management (DSM) is a way to economise the use of electricity with weather-dependent characteristics by shifting activities with high electricity demand into low-cost periods [1,2]. The classical example for DSM is the preferential use of night periods with generally lower consumption and electricity prices. Under conditions where electricity generation cannot be controlled any longer low price periods will less depend on the consumption profile rather be governed by surplus production.

For the analysis of the potential of DSM, it is sufficient to resort to data from 2012. First we look into the average daily structure of the surplus power. The dashed curve of fig. 8 represents the annually averaged surplus power during the day. It has its maximum around noon time owing to the PV contribution (subject to the optimal mix criteria). Against general expectation the periods with lower electricity prices equated with higher surplus levels occur mostly during the day and its use will intensify the economic activities in times where they are traditionally already high. This strong temporal structure of the surplus power is even more pronounced during summer months (red curve in fig. 8) but more smoothed during winter months (blue curve). Different strategies might therefore be necessary for summer and winter to make maximal use of low-price periods.

The added-up surplus energy accruing during the day (6:00 to 18:00) is $83 \mathrm{TWh}$ out of totally $131 \mathrm{TWh}$. The average surplus energy is 0.23 TWh per day. A critical issue for an economic use of surplus energy while maintaining social standards is its day-to-day variation. If the daily variation of the low-cost electricity period turns out to be small its use by periodic processes could be economic and reasonable. Otherwise, the economic benefit of a generally low price situation has to be traded off against the additional costs to adjust to electricity prices strongly varying from day to day. Plotted in fig. 9 is the surplus energy gained within $12 \mathrm{~h}$ during the day (6:00-18:00, red dots, red curve) and the night periods (blue). The surplus energy strongly fluctuates with the day values being generally larger than those during the night. The average values are also shown as curves just to identify the rough trends ${ }^{13}$. The average surplus available during the day has its maxima in January through March but is rather constant over the year whereas the average surplus collected during the night is larger than the one during the day for January and December and has a minimum close to zero during the summer months June-August. The seasonal variation during the night period reflects the stronger wind in winter and the larger PV contributions during the day in summer.

\footnotetext{
13 Because of the high scatter represented by a coefficient of variance $>1.3$, the fit is not a good representation of the actual data. The correlation coefficient is 0.47 for the night and 0.18 for the day sample.
} 


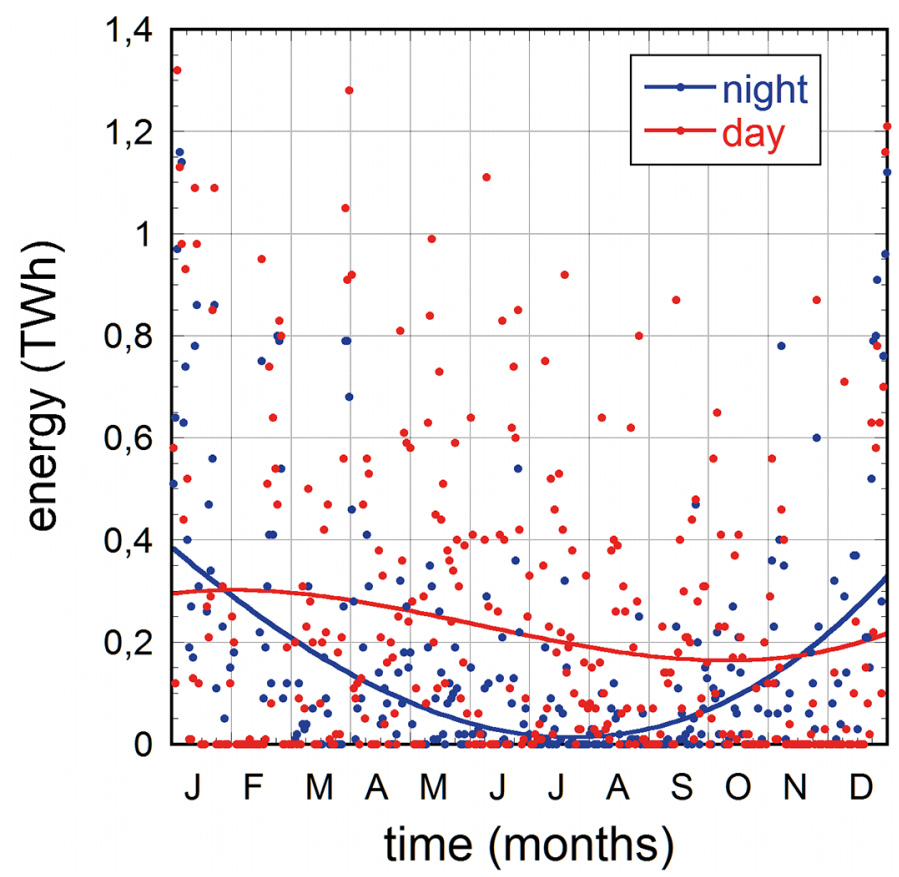

Fig. 9. Surplus energy of the $100 \%$, optimal mix case of 2012 gained within $12 \mathrm{~h}$ during the day (6:00-18:00, red dots, red curve) and the night periods (blue). The solid curves are polynomial fits to the data points.

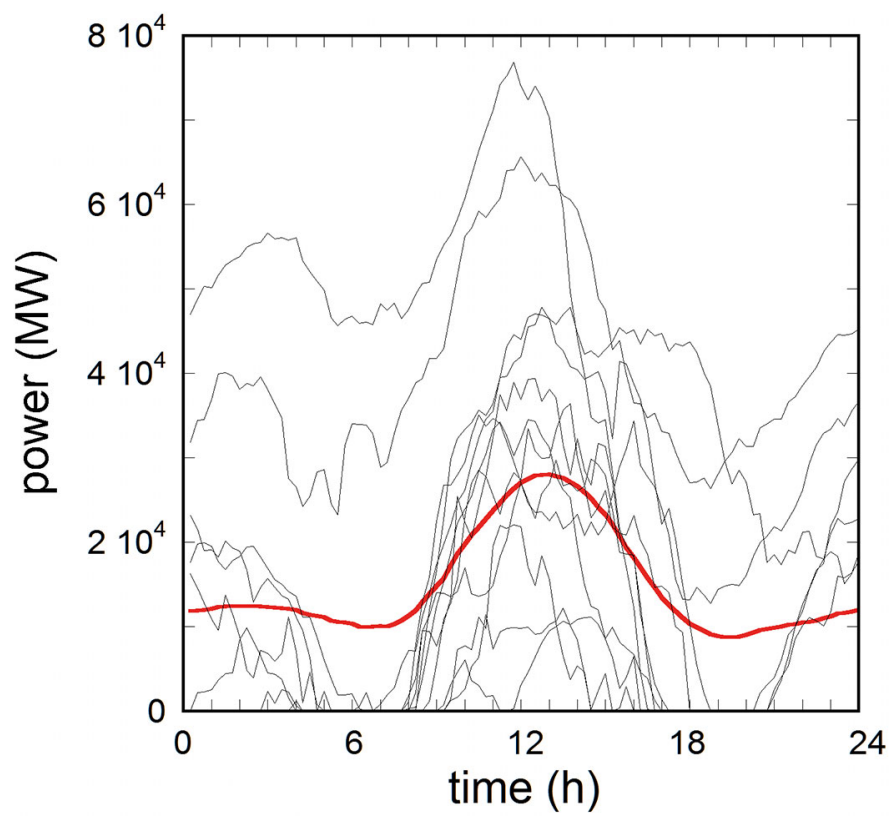

Fig. 10. Plotted is the daily surplus power for the $100 \%$, optimal mix case for three weeks in April 2012 compared with the annual average (red curve).

Figure 10 shows again the surplus power as it varies from day to day for three weeks in April 2012 together with the annual average (red curve). The surplus level strongly varies. The maximum daily surplus energy is 1.2 TWh in this period; the average one is $0.23 \mathrm{TWh}$; the standard deviation is $0.29 \mathrm{TWh}$ surpassing the average value. No surplus energy at all accrues on 134 days for which the electricity price can be expected at the standard (high) level. The adjustment of a repetitive technical process to this variability of electricity supply will increase the overall costs in the proper use of surplus power. 


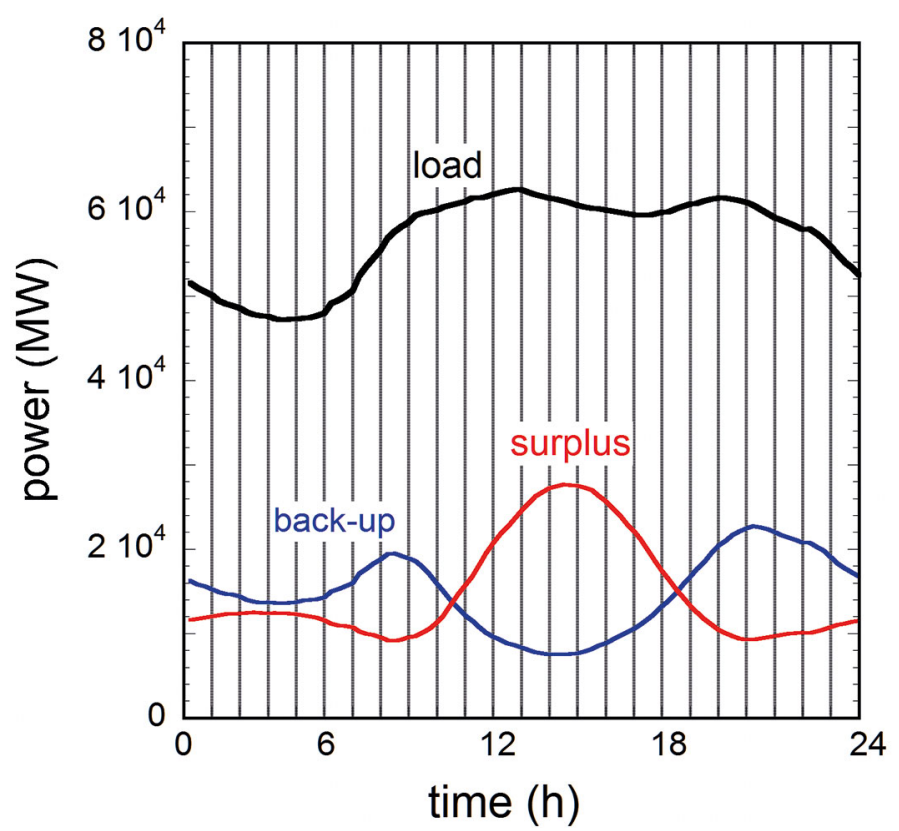

Fig. 11. Annually averaged daily surplus and back-up power for the 100\%, optimal mix case of 2012 compared with the load.

Demand-side management is a favoured concept for the transition from demand-oriented to supply-oriented electricity use. Smart grids are introduced as tools to handle and to make use of variable electricity prices. We have to conclude that the strong day-to-day variation of the available surplus electricity might shed some doubt on the proper use of surplus electricity by these means as long as working processes follow diurnal periodicity.

\section{Storage of surplus electricity}

We will first consider storage neglecting transformation losses and we will limit ourselves to the two extreme cases - day storage and seasonal storage. We will not consider singular solutions, e.g. in the combination of roof-top PV panels and matched storage systems neither do we study battery buffer systems for grid stability. As stated above, our interest is the analysis of the global supply system transformed into one based exclusively on the use of intermittent sources. These considerations do not depend on specific technical solutions ${ }^{14}$.

\subsection{Day storage}

Figure 11 shows the daily variation of the annually averaged surplus power (red) once more and compares it with the average back-up power (blue). Both curves are also compared with the daily variation of the average reduced load (black) in order to see the immediate relation between the needs and the possibilities in the use of surplus power via a day storage. We first consider one potential use of a day storage - to make the gain during the day available for the following night as fig. 11 suggests. The difference between the average surplus and the average backup energy in the period where surplus is larger than the back-up power (from 9:30 to 18:00) is 0.1 TWh. For comparison, the average daily demand is $1.36 \mathrm{TWh}$ and the average daily surplus energy (or alternatively back-up energy for the $100 \%$ scenario) is $0.36 \mathrm{TWh}$. In the average about $1 / 3$ of it can be moved from the day to the night. Like for demand-side management, the proper use of a day storage depends, however, on the day-to-day variation of the energy to be transferred.

The two plots of fig. 12 show the daily surplus energies for two months in winter and two in summer split into the day and the night periods. In winter the surpluses of day and night are rather correlated with a correlation coefficient of 0.88; in summer, this is understandably less the case. The high correlation in winter implies that surplus during the night is generally high when it is also high during the day. The correlation of surplus production between day and night shows that at least for the winter season, the concept of moving the gain during the day into the next night is not very viable. Rather, the surplus energy has to be collected over longer periods and has to be stored for later use. The winter diagram also shows a lengthy period without surplus power which lasts for more than a week. Therefore, already the use of the daily surplus requires a larger storage to cope with its accumulation over days and with the lack of surplus production for several days.

\footnotetext{
${ }^{14}$ For storage technologies, see G. Fuchs et al. Technology Overview on Electric Storage, Institut für Stromrichtertechnik und Elektrische Antriebe, RWTH Aachen, June 2012.
} 

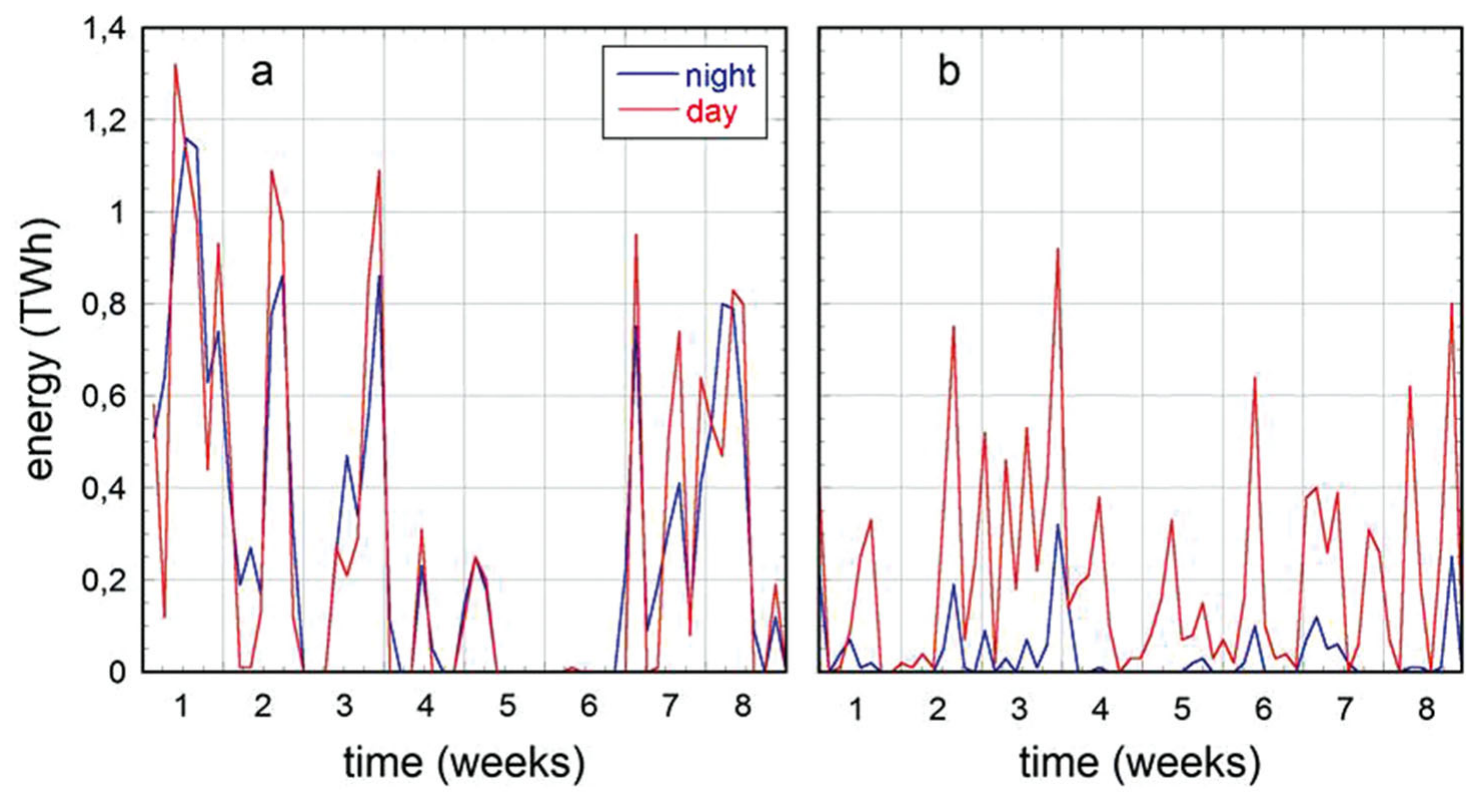

Fig. 12. (a) Daily surplus energies of the $100 \%$, optimal mix case for two months in winter (based on January and February 2012) and (b) for two in summer (July and August) split into the day and the night periods.
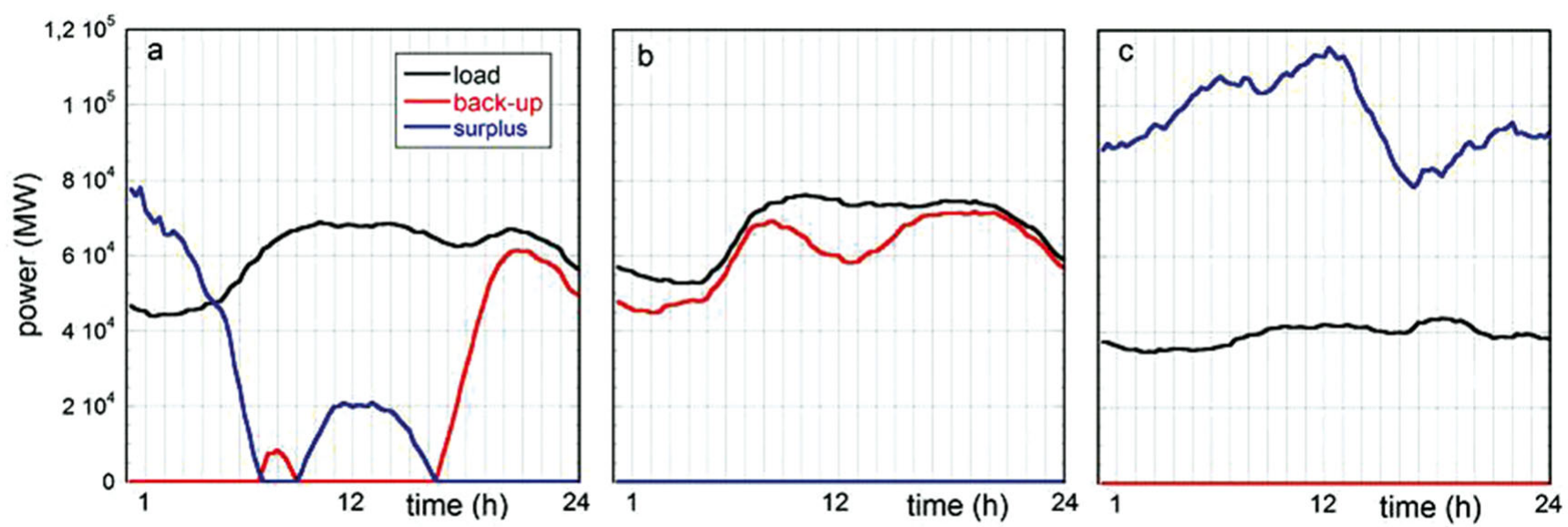

Fig. 13. Plotted are reduced load, back-up and surplus power for three cases: (a) the day (2.4.12) with the largest energy transfer from the storage to the grid; (b) the one (15.11.12) with the largest back-up need; and (c) the one (31.12.12) with the largest surplus energy.

Whereas surplus energies between day and night are correlated in winter but not in summer, a stronger correlation is observed in summer for the time difference between the maximum in load and the one of surplus power. The surplus power assumes a rather rigid profile in summer. Nevertheless, the time difference between the two maxima - load and surplus power - jump between two values, typically -2 and $+10 \mathrm{~h}$, depending on whether the load maximum is in the morning or in the evening. These phase jumps underline again that the use of surplus energy for repetitive processes is rather involved.

Next, we look into another scheme viz. to continuously fill the periods of needs where otherwise the back-up system had to help out. The day storage is specified by a capacity, which corresponds to the average daily surplus energy of 0.36 TWh. The largest surplus production based on the up scaled 2012 data is 2.33 TWh (31.12.2012), the largest need from the back-up system is $1.47 \mathrm{TWh}$ (15.11.2012). The maximal surplus use by a day storage was on April 2nd. Figure 13 shows reduced load, back-up and surplus power for the three cases considered - the one with the largest daily energy transfer from the storage to the grid (a), the one with the largest back-up need (b) and the one with the largest surplus energy (c) incurring under 2012 conditions. 


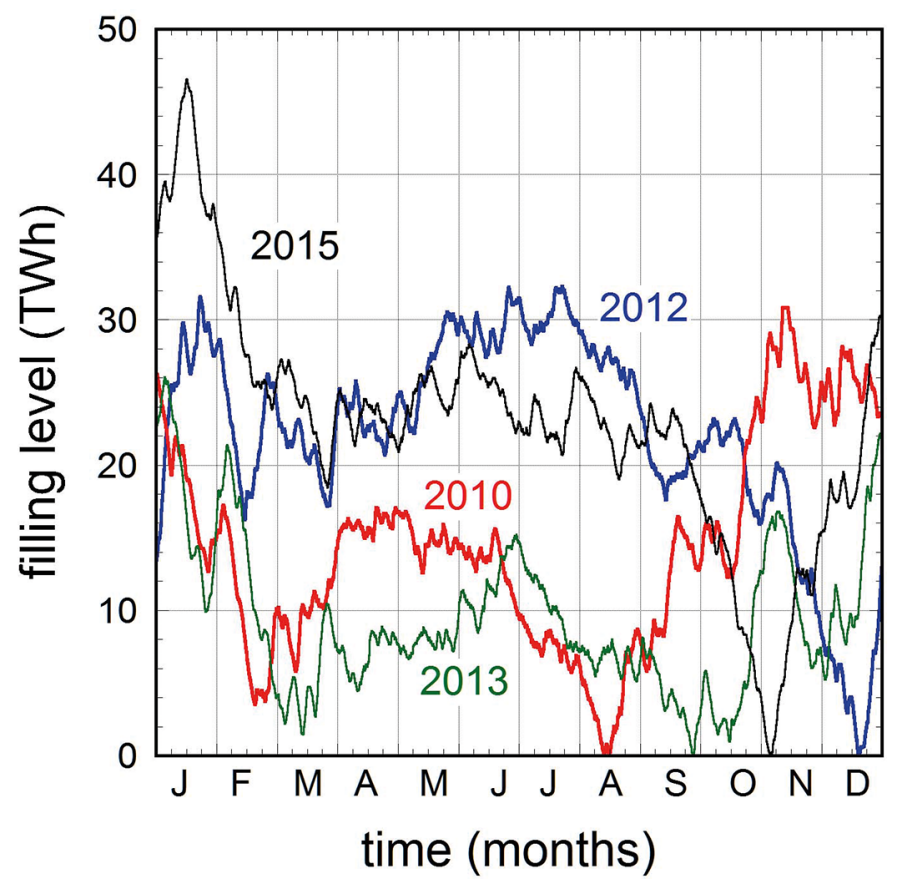

Fig. 14. Plotted is the "filling level" of seasonal storages for the weather conditions of the years 2010, 2012, 2013 , and 2015.

On April 2nd, 0.47 TWh surplus could have been collected whereas only 0.37 TWh were needed ${ }^{15}$. The maximal possible transfer of surplus energy of $0.37 \mathrm{TWh}$ corresponds just to the average daily surplus (0.36 TWh) stressing again the low effectiveness of a day storage to make proper use of the surplus offer. Over the year, a daily storage with a capacity of $0.36 \mathrm{TWh}^{16}$, which would allow handling the average daily surplus energy in 2012, would process 21.7 TWh from the total surplus of $131 \mathrm{TWh}$ and would be operational in total for 195 days. To accept the surplus power on April 2nd with the largest transfer, the day storage has to handle $80 \mathrm{GW}$. The capacity factor of such a system, when used only on a day-to-day basis, is $3 \%$, which seems to be rather uneconomic.

\subsection{Seasonal storage}

In order to use more of the $131 \mathrm{TWh}$ surplus energy, beyond the $21.7 \mathrm{TWh}$, which can be distributed on a daily basis using a storage with a nominal capacity of $0.36 \mathrm{TWh}$, requires its collection over longer periods. Figure 14 shows the "filling level" of seasonal storages for the weather conditions of the four years under study. Storage capacity and initial starting level are selected such that the maximal increase in storage filling is accommodated and that the storage is completely emptied at least once during the year. In order to make the results rather independent of these settings, the calculations start with December 1st of the previous year. With this procedure the work of the storage - the energy it contributes replacing the back-up system - reflects the filling steps owing to the surplus power and the emptying steps according to the load and does not benefit from a filling difference at the beginning and the end of the year.

For the 2012 case, the maximum level, which corresponds to the total storage capacity (losses are not yet considered), is $32 \mathrm{TWh}$ [1]. The storage is full in July and it is empty December 19th and quickly filled again thereafter. Both, storage capacity and filling level strongly depend on the weather conditions as they change from year to year. The nominal storage capacity varies between 26 TWh for 2013 and 46 TWh for 2015 . The storage is full in November for 2010 and 2012 and in January for 2013 and 2015; it is empty in August for 2010, December for 2012, September for 2013 and in November for 2015. It has to be considered in the specification of a future seasonal storage that storage level is typically at a minimum in late autumn when the overall electricity consumption increases.

Storage for surplus electricity requires high charging power of, e.g., $129 \mathrm{GW}$ for 2012 conditions (see fig. 4, right) and moderate discharging power of $73 \mathrm{GW}$ corresponding to the maximal power of the back-up system (see fig. 4, middle $)^{17}$. The work of the storage matches the available surplus of $131 \mathrm{TWh}$ and fully replaces the back-up system (no losses). At a power of $100 \mathrm{GW}$ and with a fictitious ideal cycle of $12 \mathrm{~h}$ loading and $12 \mathrm{~h}$ discharging, the storage could handle $1.2 \mathrm{TWh}$ per day, which would lead to a capacity factor of 50\%. For the figures of 2012, the actual capacity factor would only be $15 \%$.

\footnotetext{
15 In the frame of the $100 \%$, optimal mix case.

16 About 7 times the present pumped water storage capability of Germany.

17 For comparison, about $123 \mathrm{GW}$ power have been installed worldwide serving a storage capacity of $740 \mathrm{TWh}$, https:// en.wikipedia.org/wiki/Pumped-storage_hydroelectricity.
} 


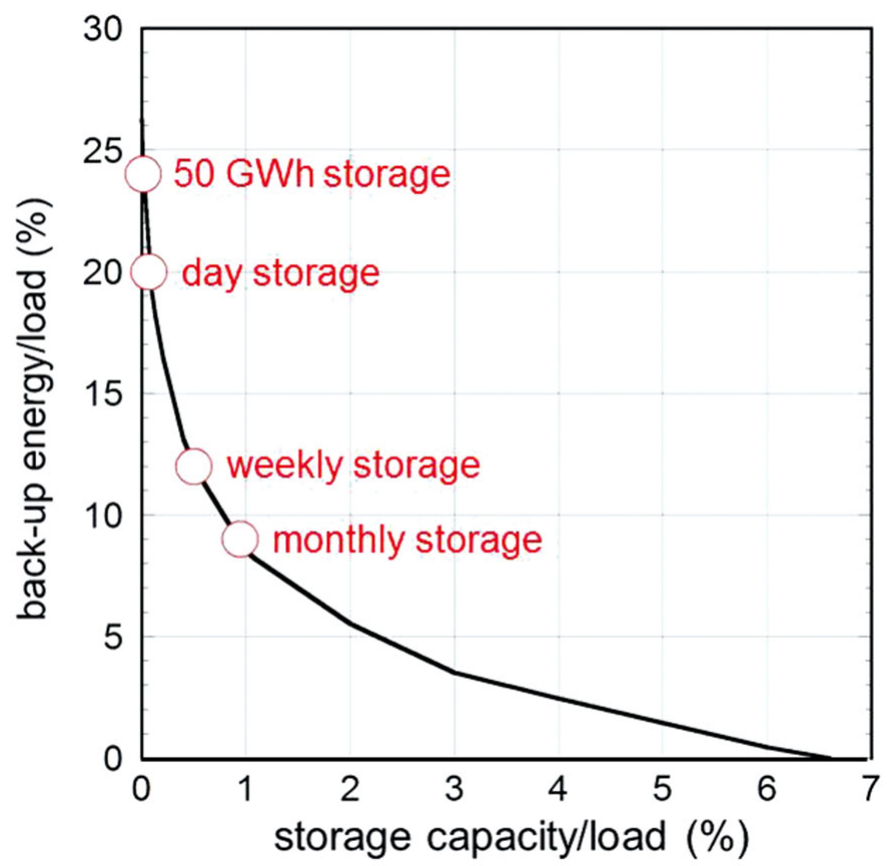

Fig. 15. Dependence of the remaining energy contribution from the back-up system on the storage capacity. Both parameters are normalised to the annual reduced load of $500 \mathrm{TWh}$. The effects of the present storage capacity $(\sim 50 \mathrm{GWh})$, a day, a weekly and a monthly storage are indicated. Losses are not considered.

The large scale technology of such a storage system for national use only does not exist at present. A lower capacity storage requires additional back-up. As is shown in fig. 15, the annual back-up energy to be additionally invested depends strongly on the size of storage. Tolerating 50 TWh from a back-up system (10\% of the target energy which agrees with the amount of exported electricity of Germany in 2015) reduces the storage capacity from 32 TWh $(6.6 \%$ of the production target of $500 \mathrm{TWh})$ down to $15 \mathrm{TWh}(3 \%)$, which is, however, still a tremendous technical challenge to develop, to realise, and to operate.

Figure 15 also shows the saving effects on back-up energy of a day, a weekly, and a monthly storage, and of a $50 \mathrm{GWh}$ storage as it is presently available in Germany in the form of pumped storage. The use of batteries of the size of Tesla Model S cars - a frequently discussed storage concept — would approximately correspond to a weekly storage if made fully available for this purpose.

Figure 15 indicates that the combination of a smaller with a larger storage would be an option. This is, however, not very effective in reducing the overall capacity demand. A small storage like the daily storage considered above, reduces the back-up power needs in periods where the iRES power is below the load. These are periods without surplus. The major part of surplus energy incurs under conditions where the iRES power surpasses fully the load (e.g., see fig. 3 left) without the need for back-up. Under these circumstances, back-up energy cannot be saved by an additional small storage and the external conditions, which specify the larger storage, are not much eased.

\subsection{Storage including transformation losses}

The future storage technology is not yet defined but it can be expected that chemical storage will play a major role [10]. For chemical storage surplus electricity produces hydrogen in the initial stage via electrolysis. Hydrogen can be directly used with fuel cells or in gas turbines to produce secondary electricity. In case hydrogen is not the envisaged final form for chemical storage it can be methanized to $\mathrm{CH}_{4}$ or further processed to higher hydrocarbons. In all cases several process steps are necessary and each of them will reduce the overall system efficiency. These efficiencies are not well known today specifically as the intermediate medium has to be produced under strongly varying electro-chemical conditions.

We split the storage process up into two stages, the filling of the storage with the efficiency $\eta_{\text {in }}$ and the transformation from hydrogen back to electricity with efficiency $\eta_{\text {out }} \cdot \eta_{\text {in }}$ addresses the transformation of primary surplus electricity into, e.g., hydrogen when we have chemical storage in mind. We assume an efficiency of $\eta_{\text {in }}=0.8$, which is above the present technical standard of typically 0.67 for this process (see ref. [11] and footnote ${ }^{18}$ ). The second

\footnotetext{
18 G. Sapy, Power to gas to power: Solution or deadlock, http://science-and-energy.org/wp-content/uploads/2016/03/ Power-to-gas-to-power-3rd-Science-and-Energy-Seminar-at-Ecole-de-Physique.pdf.
} 


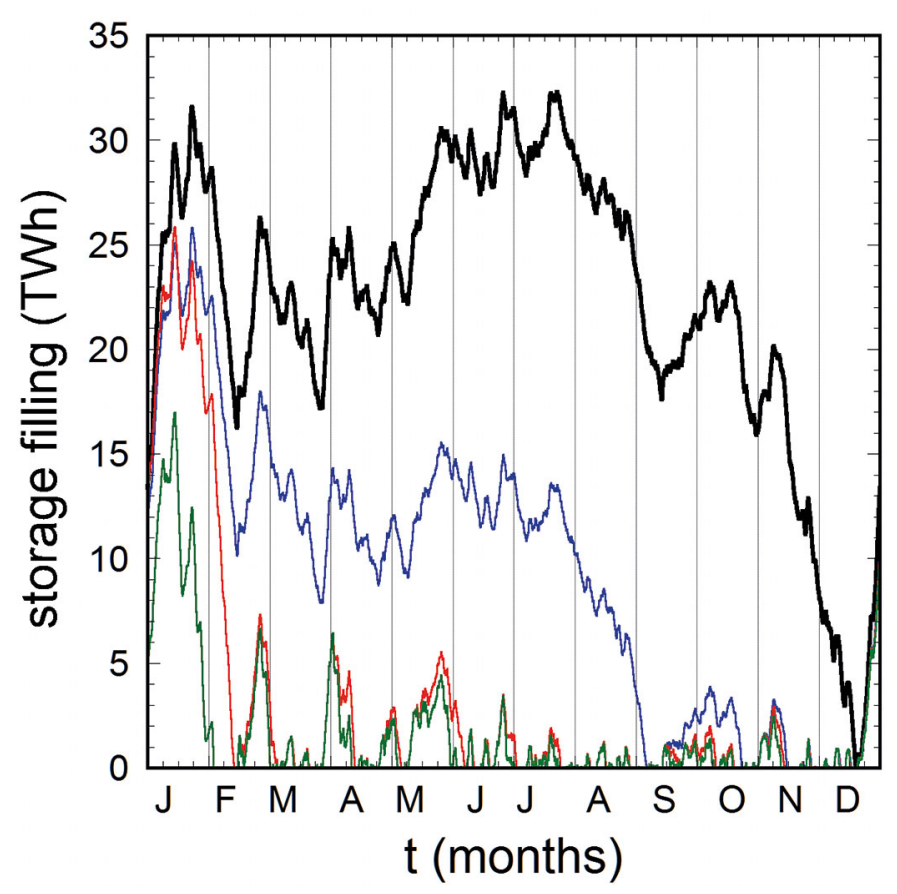

Fig. 16. Filling levels of a storage for the 100\%, optimal mix case of 2012 for ideal conditions without losses (black), the case with losses in the transformation to $\mathrm{H}_{2}$ (blue) during the storage process $(\eta=1$ assumed for the discharging periods), the case electricity $\rightarrow \mathrm{H}_{2} \rightarrow$ electricity (red) and the case electricity $\rightarrow \mathrm{H}_{2} \rightarrow \mathrm{CH}_{4} \rightarrow$ electricity employing the corresponding process efficiencies.

stage, characterized by $\eta_{\text {out }}$, deals with the transformation from hydrogen into electricity, e.g., via fuel cells or highefficiency Combined Cycle Power Plant technology. We assume $\eta_{\text {out }}=0.6$ for this scheme. Alternatively, hydrogen can be converted into methane (e.g. to utilise the large gas storage in Germany) and then converted into electricity. For this double process, we assume an efficiency of $\eta_{\text {out }}=0.4$. This is above the values typically quoted for nowadays technology of 0.15-0.2 for both stages (see ref. [11] and footnote ${ }^{18}$ ).

To begin with, we consider losses of the initial stage of hydrogen production with $\eta_{\text {in }}=0.8$. Each filling step is reduced accordingly whereas the emptying stages remain unchanged. $20 \%$ of the available surplus energy is lost in the 1st transformation step.

Figure 16 plots the filling levels of a storage based on the 2012 data for the cases considered starting with the ideal case as described above (black curve). Without losses, the available surplus is fully used and the backup power is fully replaced. With losses, this is not possible any longer. For the $100 \%$ case, the losses in the transformation to $\mathrm{H}_{2}$ for storage (blue curve) of $24.7 \mathrm{TWh}$ have to be compensated by a back-up system to meet the demand of $500 \mathrm{TWh}$. Increasing the storage capacity does not help because there is not enough surplus energy available (see next chapter). Including the losses of the 2nd transformation stage leads to a total change of the character of the storage. The storage system can only provide power shortly after periods with strong surplus production. The seasonal storage adopts the working mode of a short-term storage. In the case electricity $\rightarrow \mathrm{H}_{2} \rightarrow \mathrm{CH}_{4} \rightarrow$ electricity, the work of the storage system is only 40 TWh requiring 91 TWh back-up energy to compensate the internal losses. Such a plant is less of a storage rather a thermal system with an overall efficiency of 30\%. As the system does not operate as seasonal storage any longer, the storage capacity can be strongly reduced without losing much of the remaining efficiency. The work of the storage drops from 40 to $34 \mathrm{TWh}$. The benefit of such storage systems would be at the level of the present electricity export of Germany. The power capacity of the input stage of a system capable of contributing this work is, however, at the level of the surplus power, $130 \mathrm{GW}$.

Figure 17 plots the ADCs of the ideal storage to begin with, which would be in operation for more than half a year. Peak power corresponds to the maximal output power. This curve agrees with the ADC of the back-up system if storage is not employed. The losses in the input stage reduce the operation by about one month; the losses in the output stage further reduce the storage operation to about $31 / 2$ or $2^{1 / 2}$ months, respectively. The capacity factors, calculated from the energy contribution by the storage and the capacity of its input stage to handle the surplus power, drop from $12 \%$ for the ideal case to $9 \%$ including the losses of the input stage to $6 \%$ or $4 \%$, respectively, considering the losses in the output stage also.

One can conclude that storage systems for closing the iRES electricity supply loop based on the $100 \%$, optimal mix scenario are questionable. 


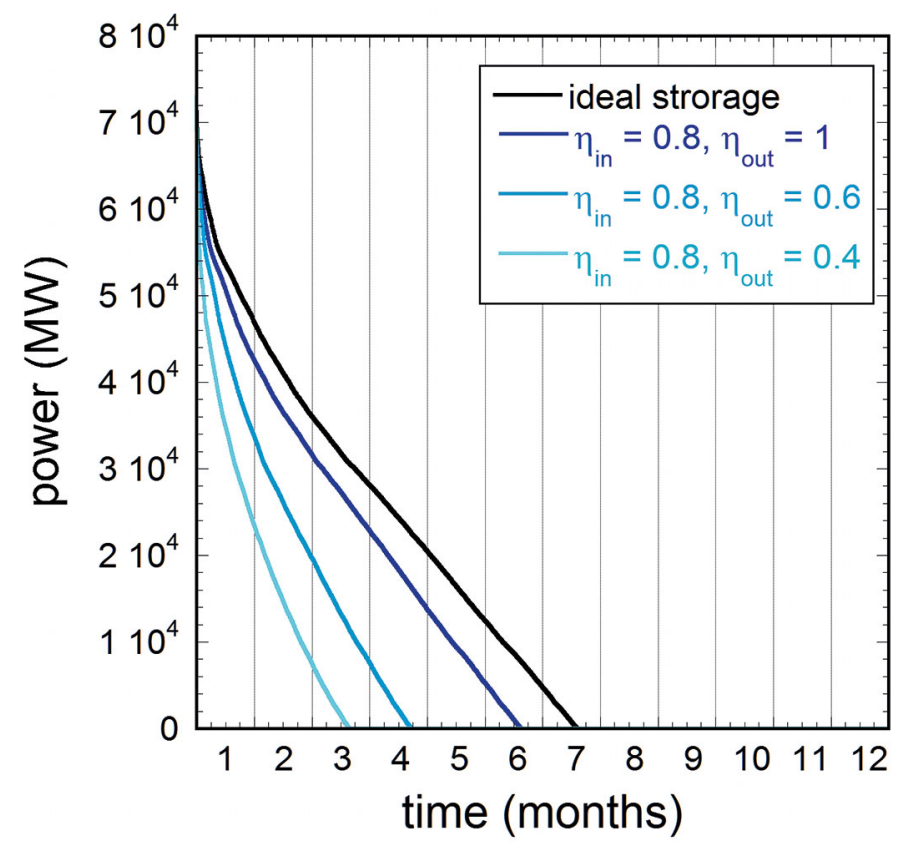

Fig. 17. Annual duration curves of discharging power of an ideal storage for 2012, optimal mix conditions (black) and in blue those with losses of the input and output channels.
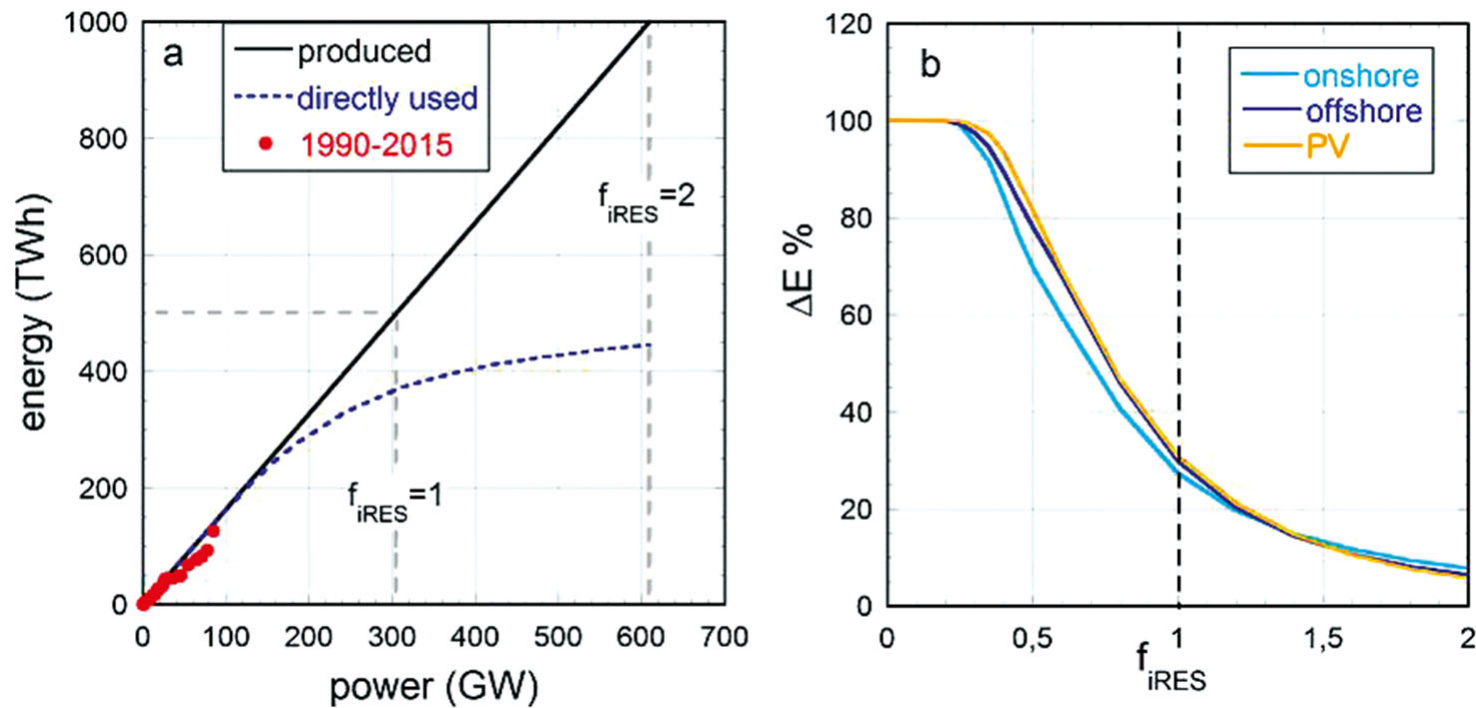

Fig. 18. (a) Plotted is the produced iRES energy (solid line) and the directly used electricity (dotted curve) under the optimal mix conditions versus the installed power together with the actual data for the years 1990 to 2015 of Germany. $f_{\mathrm{iRES}}=$ $E_{\mathrm{iRES}}{ }^{\text {prod }} /$ load; the $f_{\mathrm{iRES}}=1$ and $f_{\mathrm{iRES}}=2$ lines are indicated. (b) Plots of the energy $\Delta E$ harvested in form of directly used electricity by adding $10 \mathrm{GW}$ of on- or off-shore wind or PV power, respectively, to the existing power expressed in terms of $f_{\mathrm{iRES}}$.

\subsection{Overproduction of electricity and storage}

Because of these limitations, we consider next the viability of storage under the conditions of overproduction by iRES beyond the $100 \%$ case. The production parameter is $f_{\mathrm{iRES}}=E_{\mathrm{iRES}}{ }^{\text {prod }} /$ production target $(500 \mathrm{TWh})$. $f_{\mathrm{iRES}}$ is varied up to 2, which is enough to demonstrate issues and consequences of overproduction. Replacing the present end energy use of Germany by iRES would require $f_{\text {iRES }}$ to increase up to 4. Assuming savings in transport efficiency with electrovehicles and the replacement of oil and gas for heating by other means (insulation, electric heating) and reasonable savings for industry and commerce, $f_{\text {iRES }}$ might reach up to 2.7 .

First we present the overall characteristics of overproduction of electricity by iRES on the basis of the 2012 data. Figure 18(a) shows the produced energy (solid line) plotted versus the installed power of iRES as the sum of the three contributions - on- and off-shore wind and PV. The wind to PV energy ratio is according to the optimal mix; onshore is $2 / 3$ of the wind contribution. The $100 \%$ case is reached at $306 \mathrm{GW}$. The red dots represent the electricity contributed 


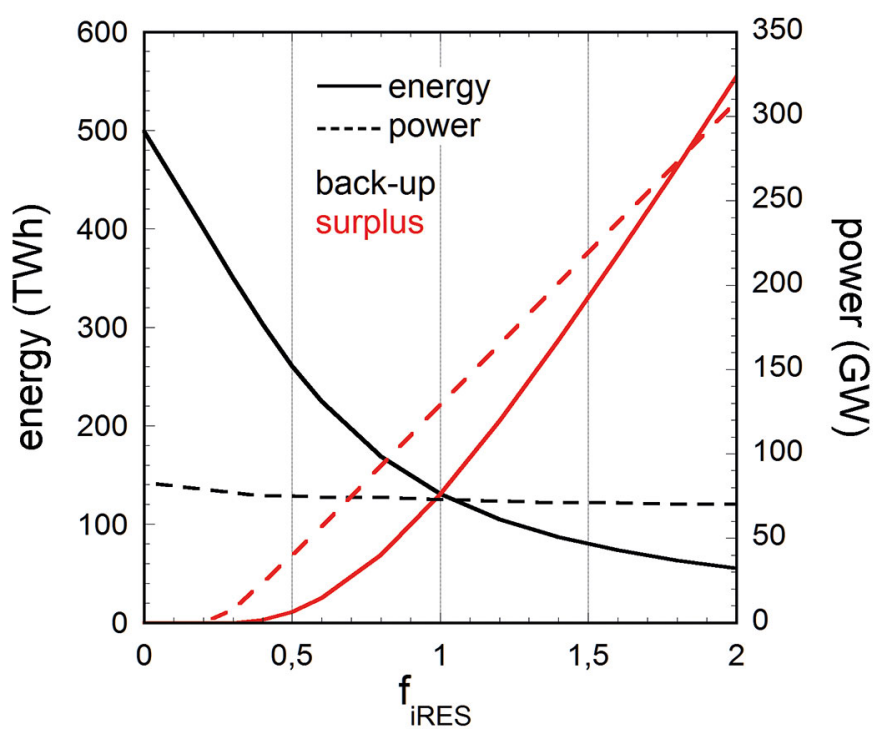

Fig. 19. Plotted are energies (solid curves) and power levels (dashed curves) of the back-up system (black) and the surplus (red) versus fiREs.

by iRES from 1990 to 2015 in Germany. The present situation — documented up to 2015 - is still in the linear range of energy versus power where the directly used energy is proportional to the installed power. This dependence will actually not continue because increasingly less efficient locations have to be occupied by, e.g., onshore wind turbines. This aspect is not further considered in this paper. The dotted curve in fig. 18(a) represents the primary electricity, which is the directly used iRES energy to meet the load which, however, strongly saturates. The saturation starts at about $120 \mathrm{GW}$ (and $200 \mathrm{TWh}$ ), when the iRES contribute with about $40 \%$ to the energy demand $[1,2]$. The reason for the saturation is the growing production of surplus electricity which cannot directly be used. Because of the saturation shown in fig. 18(a), each GW intermittent power, which is added to the stock, has less value in terms of primary electricity generation than the previous one. Figure 18(b) exemplifies this aspect showing the energy $\Delta E$ harvested in form of directly used electricity by adding $10 \mathrm{GW}$ power. It is discriminated whether the $10 \mathrm{GW}$ are from on- or off-shore wind or PV power. $\Delta E$ is constant up to the critical level of $f_{\text {iRES }} \sim 25 \%$ which corresponds to $125 \mathrm{TWh}$. In 2015, wind and PV power produced about 122 TWh. 2015 was very effective as it was a very windy year (see also right data point of fig. 18(a)). The further extension of intermittent power is expected to noticeably increase surplus production in Germany. The consequence is that the additional installations are less economic as long as there is no proper use for surplus electricity. At a low installed power level, $10 \mathrm{GW}$ allow to harvest about 15,40 and less than $10 \mathrm{TWh}$ for onshore, offshore or PV power, respectively; the production collapses to about $1 / 3$ of these figures for the $100 \%$ case $\left(f_{\text {iRES }}=1\right)$ and to less than $10 \%$ for $f_{\text {iRES }}=2$.

Now, we turn to integral values of a system designed for overproduction. Plotted are in fig. 19 firstly the energies produced and secondly the power levels of the back-up system and the surplus for $0 \leq f_{\mathrm{iRES}} \leq 2$. The back-up energy decreases continuously with increasing iRES generation starting from the peak load of $83 \mathrm{GW}$ to $73 \mathrm{GW}$ at $f_{\mathrm{iRES}}=1$ down to $70 \mathrm{GW}$ at $f_{\mathrm{iRES}}=2$. Because of the periods without wind and sun the back-up system has to remain with sufficient capacity. An economic use of the back-up facilities is, however, not provided because the capacity factor $c f=0.14$ for $f_{\text {iRES }}=1$ and 0.08 for $f_{\text {iRES }}=2$. The tendency to saturation toward high installed powers also shows that the back-up system cannot be replaced by iRES as long as we want to stay within practical and economic limits. Such a limit could be reached, e.g., at $f_{\mathrm{iRES}}=2$ when the surplus energy surpasses the target consumption of $500 \mathrm{TWh}$. Using the German grid to collect the surplus, the grid power level strongly increases up to $360 \mathrm{GW}^{19}$, which is a factor of 4.3 above peak load. The peak power values of surplus electricity increase up to $300 \mathrm{GW}$. The handling of such peaks will be a tremendous technical challenge in the use of surplus power. This affects, e.g., the technical specification of the initial stage in the storage technology or, in the case of sharing surplus power within an EU-wide grid, the layout of the interconnectors [3].

In the next step, we replace the back-up by a storage system. Losses are neglected. The results are shown for $f_{\text {iRES }}>1$ because the operation with storage of reasonable capacity requires - as we have seen - high levels of surplus. The $100 \%$, optimal mix case needs an annual storage with a capacity of $32 \mathrm{TWh}$ (for 2012 conditions). With increasing $f_{\text {iRES }}$ more and more iRES energy is directly used and the storage capacity can be strongly reduced as shown in fig. 20.

\footnotetext{
19 The new cables projected for Germany to distribute wind power from the north to the south have typically $10 \mathrm{GW}$ power transfer capability.
} 


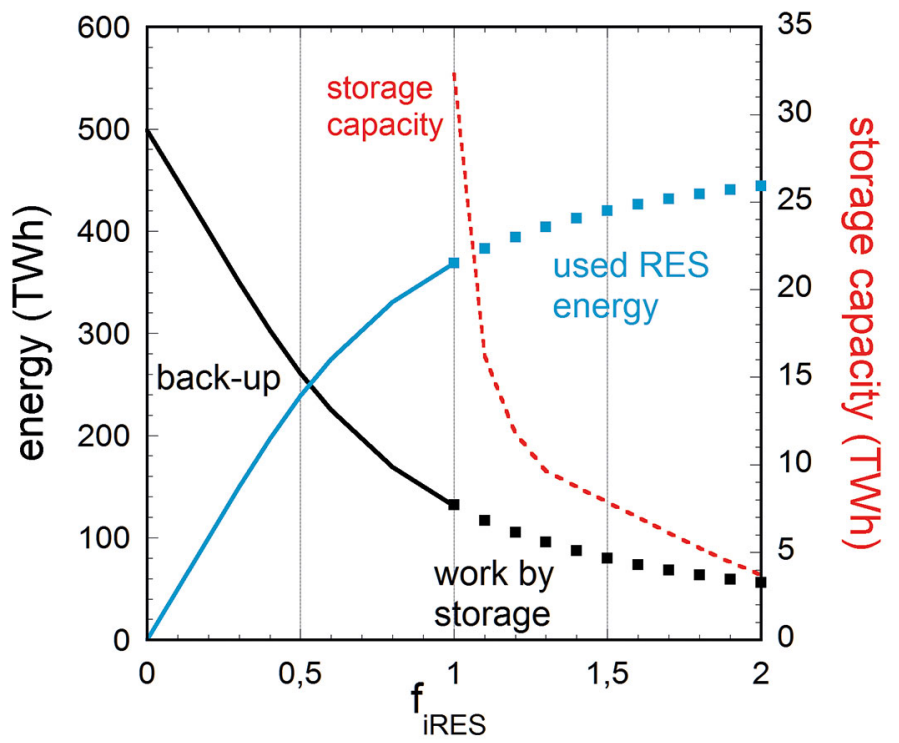

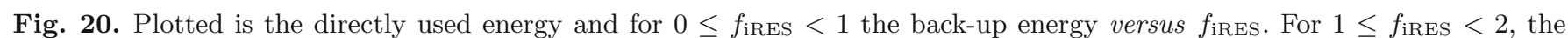
variation of the storage capacity (right ordinate) is plotted along with the work done by the storage.

Already an overproduction by $10 \%$ reduces the storage capacity to $16.2 \mathrm{TWh}$. The directly used energy is, of course, not changed by storage but the back-up contribution is replaced by the work done by the storage system. For $f_{\text {iRES }}=2,610 \mathrm{GW}$ iRES produce $1000 \mathrm{TWh}, 445 \mathrm{TWh}$ are directly used as primary electricity and $55 \mathrm{TWh}$ could be contributed by a storage with $3.6 \mathrm{TWh}$ capacity - nearly a factor of 10 smaller than the seasonal storage for the $100 \%$, optimal mix reference case. However, storage becomes irrelevant under these conditions where only $9 \%$ of the demand is processed by it. Still, the storage capacity has to be larger by a factor of 70 compared with the presently realised pumped water storage capacity of Germany.

The situation can be summarised as follows based on the data of 2012: for the 100\%, optimal mix case, $500 \mathrm{TWh}$ iRES are produced by $306 \mathrm{GW} ; 369 \mathrm{TWh}$ are directly used, the rest is supplied by a back-up system or alternatively by a storage system with $32 \mathrm{TWh}$ capacity (no losses) to handle $131 \mathrm{TWh}$ surplus. The $f_{\text {iRES }}=2$ case requires twice the power installations and produces twice the energy (in the frame of our considerations). The back-up contribution drops in this case down to $55 \mathrm{TWh}$, which can be substituted by a storage system with 3.6 TWh capacity. Facing the high primary electricity production with $f_{\mathrm{iRES}}=2$, both storage and back-up systems would be rather irrelevant, e.g., the missing energy of $55 \mathrm{TWh}$ agrees with the presently exported electricity of Germany. The problems of this high production case are rather the large installations necessary and the tremendously large surplus energy. Figure 21 shows the development of the surplus energy. It increases from $131 \mathrm{TWh}$ at $f_{\mathrm{iRES}}=1$ to $555 \mathrm{TWh}$ at $f_{\mathrm{iRES}}=2$. The dashed line in fig. 21 shows the remaining surplus collected in periods where the storage is full. For $f_{\text {iRES }}=2,500$ TWh are surplus without further use in the first instance. A storage larger than 3.6 TWh would not help in this case, it only would not be emptied during the year.

We consider next two storage cases with losses - one with moderate overproduction at $f_{\text {iRES }}=1.25$ and one with strong overproduction at $f_{\mathrm{iRES}}=2$. The $f_{\mathrm{iRES}}=1.25$ case would compensate the losses in the transformation to $\mathrm{H}_{2}$. However, the total energy balance is different in this case, whereas, with $f_{\mathrm{iRES}}=1,370 \mathrm{TWh}$ are directly used, this value increases to $400 \mathrm{TWh}$ with $f_{\mathrm{iRES}}=1.25$. The rest to meet the $500 \mathrm{TWh}$ goal, $100 \mathrm{TWh}$, is contributed by the storage with $32 \mathrm{TWh}$ capacity for the case $\eta_{\text {in }}=0.8, \eta_{\text {out }}=0.6$. In the $\eta_{\text {in }}=0.8, \eta_{\text {out }}=0.4$ case, the storage contributes with $71 \mathrm{TWh}$ requiring an additional back-up system contributing with $29 \mathrm{TWh}$. This contribution is unavoidable and can be reduced only by large capacities even more outside of any practical value. The operational conditions of the storage with $f_{\text {iRES }}=1$ and $\eta_{\text {in }}=0.8, \eta_{\text {out }}=0.6$ are represented by a capacity factor of $c f=6 \%$, the $f_{\text {iRES }}=1.25$ case with the same losses by $7 \%$. We can again conclude that storage systems with moderate overproduction have hardly a chance of realisation. The case of strong overproduction with $f_{\mathrm{iRES}}=2$ has no relevance for storage either. In this case, $445 \mathrm{TWh}$ can directly be put into the grid, however at exorbitant peak power levels of $360 \mathrm{GW}$. The missing 55 TWh can hardly be discussed in the frame of storage.

It is questionable to utilise electricity surplus to generate secondary electricity with intermediate transformation steps in between. As a consequence, alternative uses of surplus electricity have to be considered. The production of hydrogen would be an option with fewer losses. $1 \mathrm{MW}$ of electricity allows producing $180 \mathrm{Nm}^{3} / \mathrm{h} \mathrm{H}_{2}$. With the $131 \mathrm{TWh}$ surplus of the $100 \%$, optimal mix case, about $20 \mathrm{Mrd} \mathrm{m}^{3} \mathrm{H}_{2}$ could be produced, which would allow to meet the annual $\mathrm{H}_{2}$ consumption of German industry. 


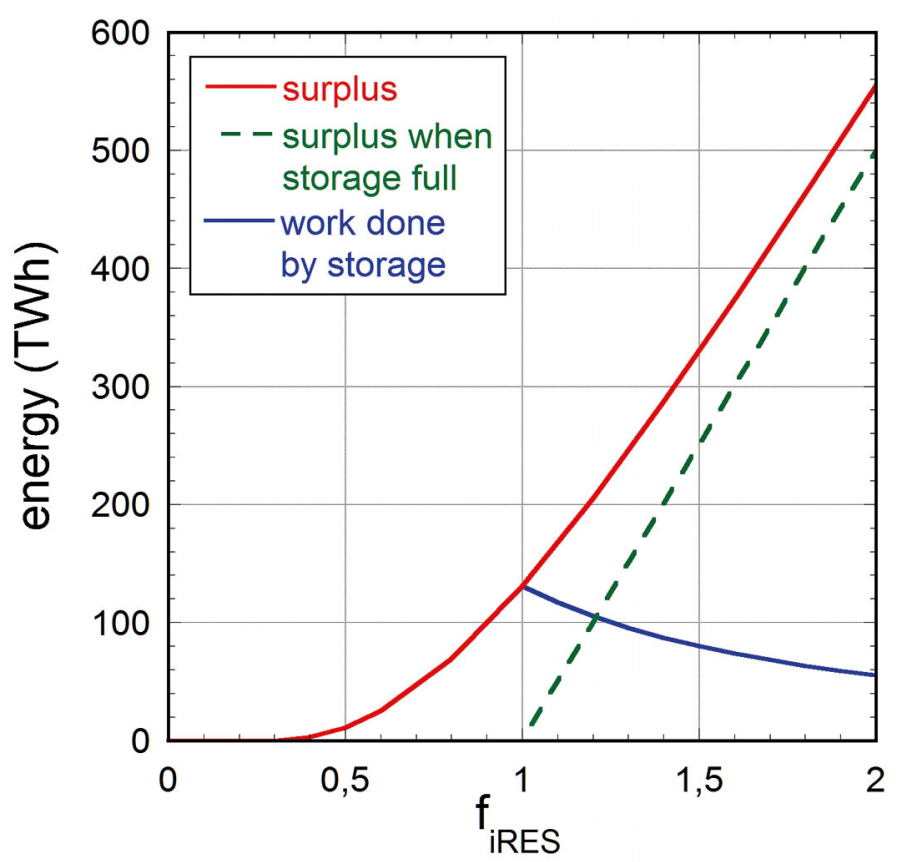

Fig. 21. Compared are the surplus energy, the remaining surplus collected in periods where the storage is full and the work, done by the storage for various $f_{\text {iRES }}$.

In order to avoid transformation losses, a direct use of the surplus electricity should be considered. The most appropriate form would be the use for electric heating. The demand for heating of buildings is presently about $38 \%$ of the final energy consumption ${ }^{20}$ amounting to $920 \mathrm{TWh}$ for 2012 . If surplus of the $100 \%$, optimal mix case $\left(f_{\mathrm{iRES}}=1\right)$ is fully used, $14 \%$ of the heating demand can be covered. The $f_{\text {iRES }}=2$ case allows formally to cover $60 \%$ of the demand.

\section{Conclusions}

In this paper we have analysed various aspects of an electricity supply system based on renewable energies with intermittent character (iRES). The analysis is carried out for the years 2010, 2012, 2013 and 2015 using demand and supply data of Germany. Thereby, year-to-year variations are noted. The system characterisation is done in the frame of a nominal $100 \%$ supply by wind and photovoltaic power with the "optimal mix" between these two supply forms. A complete supply requires an installed iRES power which is about four times the peak load. For a nominal $100 \%$ supply, surplus electricity accrues at an energy level of $26 \%$ of the total demand. Surplus substantially surpasses the total PV production and compares for the German case nearly with the electricity consumption of Poland or Sweden. For Germany in 2015 the directly used iRES energy by wind and PV is still proportional to the installed power, nevertheless, German electricity export rises up to $50 \mathrm{TWh}$ in 2015 roughly in proportion to the annual PV production. The further extension of intermittent power is expected to noticeably increase surplus production.

The electricity sources of the iRES system are characterised by a low integral capacity factor of about $18 \%$. As a consequence of surplus production and in the frame of nominally 100\% supply, a wind and PV power based iRES system has to be supplemented by a back-up system of about $89 \%$ of peak load — as long as storage technology is not provided. As nuclear power stations drop out for back-up, the power of fossil power stations has to increase even above the presently installed capacity of Germany. For given installed power and the case considered here, the produced iRES energy can vary by about $\pm 15 \%$ from year to year. These weather-dependent characteristics and their variability have to be considered in the design of an electricity supply system with predominantly intermittent generation. The run-off hydro-electricity production of Norway — an example of an exclusive weather-dependent supply — varies also by about $\pm 17 \%^{21}$ with low years being backed, however, by storage.

Because of the high installed iRES power the grid and all subsystems have to operate at a high power level, which is more than a factor of 2 above peak load. Cutting power peaks and curtailing iRES production as a means to cope with surplus leads to substantial losses. It could be that considerations regarding system economy do not allow this scheme to ease the technological challenges.

\footnotetext{
${ }^{20}$ http://www.iwu.de/fileadmin/user_upload/dateien/energie/ake48/IWU-Tagung_2012-0531_Bigalke_dena_ BedarfVerbrauch.pdf.

${ }^{21}$ www.regjeringen.no/globalassets/upload/oed/pdf_filer/faktaheftet/evfakta08/evfacts08_kap02_eng.pdf.
} 
Demand-side management is a favoured concept for the transition from demand-oriented to supply-oriented electricity use. Smart grids are introduced as proper tool to handle and to make use of variable electricity prices. In the average, surplus electricity accrues during the day owing to PV. If the concomitant low-price period is to be used for economic purposes, the activities during the day will be further accentuated. However, the strong day-to-day variation of the available surplus electricity might shed some doubt on the proper use of surplus electricity by these means as long as working processes are adjusted to diurnal periodicity. Different strategies might be necessary for summer and winter to make optimal use of low-price periods. The best use of the potential of demand-side management seems to be the integration of the weekends into economic activities [1].

Large-scale storage technology is necessary to replace a back-up system based on fossil fuels. But this technology is not yet available and will require years of basic research in the case of chemical storage. System studies as done here do not require detailed knowledge on specific technologies rather can be based on specified transformation efficiencies. Two characteristic cases are considered. A day-storage can be used to move excess energy into periods of short-term shortages. Such a scheme has to cope with the strong variation of surplus energy from day to day. A general limitation of short-term storage is the correlation of surplus production between day and night periods in winter suggesting the need for larger storage. A seasonal storage in the strict sense requires a very large capacity whereas the filling curve is found to depend strongly on the individual weather conditions during the year. This aspect has to be considered in the specification of a future seasonal storage. The storage capacity can be strongly reduced when the requirement for a 100\% supply by intermittent sources is liberated and other sources of dispatchable power are allowed. A seasonal storage can only be meaningfully assessed when transformation losses are considered. But a real seasonal storage will never act as such because the internal losses will change its operational character. It will not work continuously during the year rather in periods only with preceding phases of large surplus production. In such situations, the storage will operate for short intervalls. The internal losses will transform the storage into a thermal system with low overall efficiency. An ideal system will operate like the back-up system for more than half a year. With losses, operation reduces to ultimately 2.5 months $^{22}$ with a capacity factor of $4 \%$ in the case that hydrogen and methane are the intermediate energy carriers. The low $c f$-values are caused by the high power capability of the input stage of a storage system designed to handle the high power level of surplus electricity.

The case of overproduction to increase surplus power is found to have no relevance for storage either. The need for large storage capacities decreases quickly as more iRES energy is provided for direct use. Strong overproduction (e.g., twice the generation of the $100 \%$ case) leads to small remaining demands, which can easily be covered by other means and will hardly be met by a complex storage system necessitating high technical investments. The large installed production capacity, the high grid power level and the large amount of surplus electricity, which accrues in this case, are the major technical and economic obstacles. We conclude that seasonal storage systems for closing the electricity supply loop based exclusively on iRES are unlikely to become reality. Facing the tremendous technical effort they seem to be far from any economic value. The direct use of surplus electricity, e.g., for hydrogen production for industrial purposes or household heating, seems to be the most appropriate application.

In this paper, we have not considered biomass and waste, which contributed with about 50 TWh to electricity production in Germany in 2015. In the future when wind and PV power meet a large part of the electricity demand, one can expect that bio-mass will be preferentially used for aviation and heavy duty transportation. A strategy to make one branch totally $\mathrm{CO}_{2}$-free does not make much sense blending out other ones with even higher emission (see the difference between total GHG and $\mathrm{CO}_{2}$ emission due to electricity production as documented in fig. 22). It will be difficult to triple the biomass electricity output to meet the back-up need and to avoid electricity storage facing the presently growing import of biomass [12] and the losses of agricultural bio-diversity already nowadays evident in German rural areas.

The German transformation policy, dubbed Energiewende, includes the termination of nuclear energy. Initiated by the Fukushima catastrophe in 2011 nuclear power will be phased out till 2022 and replaced by iRES, mostly wind and $\mathrm{PV}$ power. In this period, Germany will not contribute in reducing its $\mathrm{CO}_{2}$-output from electricity generation because predominantly, one $\mathrm{CO}_{2}$-free supply technology is replaced by another one.

The $\mathrm{CO}_{2}$ release caused by electricity production in the period from 2002 up to 2015 is shown in fig. 22 and reflects the changes in the generation and the production mix. In the average, the $\mathrm{CO}_{2}$ production dropped in this period by $\sim 0.6 \%$ per year. The tendency to decrease is reflected by the data points of 2002 up to 2006 and later by the data points of 2014 and 2015 .

In the period from 2010 to 2015 the electricity consumption is about $523 \mathrm{TWh}$ and decreases slightly with about $0.16 \%$ per year. This trend is expected to continue till 2022. In order to estimate the $\mathrm{CO}_{2}$-production up to 2022 an assumption on the development of the total electricity production, which is responsible for the national $\mathrm{CO}_{2}$ generation, has to be made. It is assumed that nuclear power is replaced by wind and PV power at a rate as politically planned. To nominally replace $20 \mathrm{GW}$ nuclear power about $100 \mathrm{GW}$ renewable power are required. Reasonable assumptions have been made for the development of other sources contributing to electricity generation. German electricity export is kept constant at the 2015 level. To assume no electricity export in the time frame considered seems to be unrealistic

\footnotetext{
${ }^{22}$ Based on 2012 data.
} 


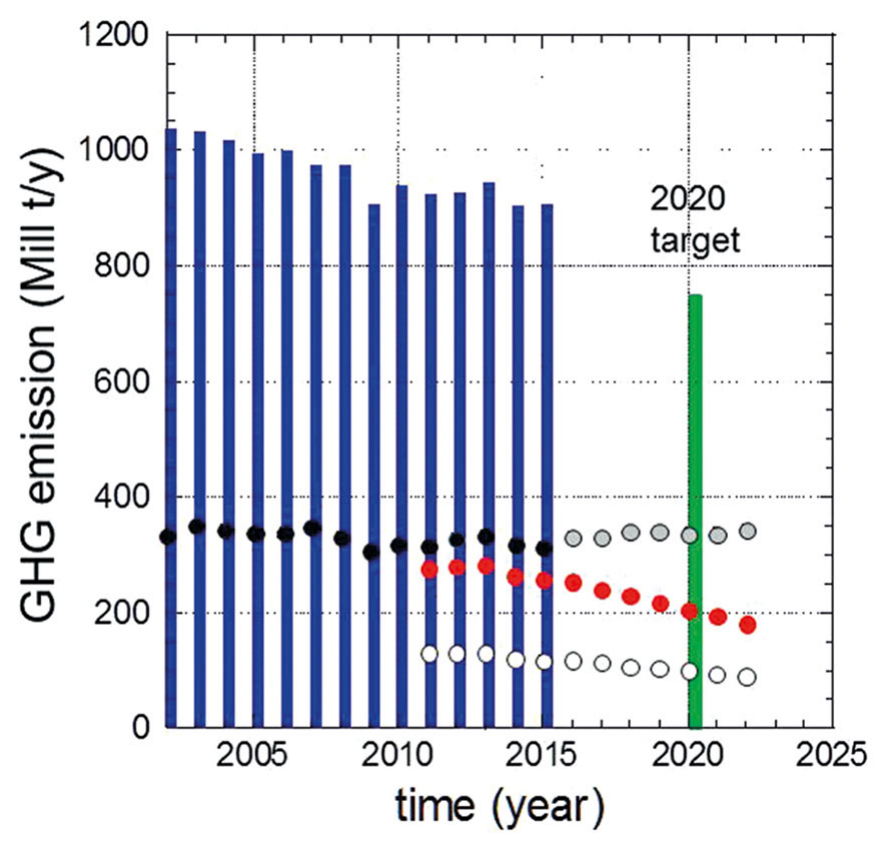

Fig. 22. Plotted is the greenhouse gas (GHG) emission of Germany ${ }^{23}$ from 2002 to 2015 and the political target of 2020 (bars). The black data points represent the specific $\mathrm{CO}_{2}$ generation from electricity production up to 2015 and beyond the expected one up to 2022. The red dots represent the hypothetical $\mathrm{CO}_{2}$ emission if lignite instead of nuclear power station were gradually phased out; the open circles represent the case that all coal burning power stations had been replaced by gas ones in 2011.

facing the surplus production of intermittent iRES and the limited balancing capability of fossil fuel stations. From the 186 TWh electricity expected to be contributed by wind and PV in 2022 about 30 TWh can accrue as surplus energy ${ }^{23}$.

By 2022, an extremely oversized power supply system has to be created, which can be expected to continue running down spot-market electricity prices. The continuation of the economic response - to replace gas fuel by the cheapest one which is lignite - causes an overall increase in $\mathrm{CO}_{2}$ emission. Indeed the $\mathrm{CO}_{2}$ emission of Germany caused by electricity generation is expected to increase from 317 Mill t in 2010 to 344 Mill t in 2022.

An effective contribution to the existing environmental problems would have been to stop lignite burning instead of switching off nuclear power stations. In this case, the specific $\mathrm{CO}_{2}$ emission would drop to 181 Mill t. If additionally coal were totally replaced by gas, the $\mathrm{CO}_{2}$ emission would further drop down to 91 Mill t.

Figure 22 shows the actual development of the specific $\mathrm{CO}_{2}$ emission of Germany from 2002 to 2015 and the expected one up to 2022 along with the hypothetical ones with lignite instead of nuclear power being phased out and the one with gas as the only remaining fossil fuel from 2011 on. Shown is also the political GHG emission target for 2020 (749 Mill t/y). It is obvious that this target cannot be met by the power system alone on the basis of the Energiewende in its present form and that there is a clear conflict between political goal and applied method to reach it. The switch-off of lignite instead of nuclear power combined with increased use of gas would have opened a way to reach the 2020 target by the electricity generation system itself. Without $\mathrm{CO}_{2}$-free storage technology and even with a gas fuelled back-up system, Germany in 2050 will not meet the specific $\mathrm{CO}_{2}$ emission level, which characterises those European countries since decades like Sweden, Switzerland and France, which benefit from hydro-electricity and employ nuclear power [2,8].

In this paper we have concentrated on electricity generation only and assessed the technical consequences of the intermittent nature of wind and PV power because these two technologies can be scaled to large production rates when the necessary land and funding are provided. But de-carbonisation of a complete economy requires also the replacement of chemical energy in other private and economic sectors. At present, electricity consumption corresponds to about $21 \%$ of the German end energy needs ${ }^{24}$. The comparison of the greenhouse gas emission of Germany with the specific $\mathrm{CO}_{2}$-emission by electricity production (fig. 22) shows the challenge of this task and the complexity of replacing the present primary energy supply based predominantly on chemically stored energy by electricity as future source also for other forms of energy use. Here, we have argued that overproduction by iRES may not be the right way to go. The impact on land use and the transformation of landscape, e.g., by wind convertors and transmission lines at an unprecedented density will intensify social resistance. Therefore, it is mandatory to consider also other forms of $\mathrm{CO}_{2}$-free energy production to supplement iRES.

\footnotetext{
${ }^{23}$ Calculated on the basis of the weather conditions of 2012.

23 http://www . umweltbundesamt.de/themen/klima-energie/energieversorgung/strom-waermeversorgung-in-zahlen.

24 Defined as total primary energy production minus energy required internally for power production and minus transport losses.
} 
Open access funding provided by Max Planck Society (or associated institution if applicable).

Open Access This is an open access article distributed under the terms of the Creative Commons Attribution License (http://creativecommons.org/licenses/by/4.0), which permits unrestricted use, distribution, and reproduction in any medium, provided the original work is properly cited.

\section{References}

1. F. Wagner, Eur. Phys. J. Plus 129, 20 (2014).

2. F. Wagner, Eigenschaften einer Stromversorgung mit intermittierenden Quellen, in Energie: Erzeugung, Netze, Nutzung, edited by H. Bruhns (DPG, 2015) p. 138.

3. F. Wagner, Eur. Phys. J. Plus 129, 219 (2014).

4. D. Grand et al., Eur. Phys. J. Plus. 131, 329 (2016).

5. D. Grand et al., Techniques de l'Ingénieur, IN-301 (2015).

6. D. Grand et al., Transition énergétique et mix électrique: les énergies renouvelabels peuvent-elles compenser une réduction du nucléaire?, in Revue de l'énergie, Vol. 619 (2014).

7. F. Romanelli, Eur. Phys. J. Plus 131, 53 (2016).

8. F. Wagner, E. Rachlew, Eur. Phys. J. Plus 131, 173 (2016).

9. F. Wagner, F. Wertz, Eur. Phys. J. Plus 131, 284 (2016).

10. R. Schlögl (Editor), Chemical Energy Storage (De Gruyter, 2012) ISBN-10: 3110264072, ISBN-13: 978-3110264074.

11. H. Pütter, Die Zukunft der Stromspeicherung, in Energie: Technologien und Energiewirtschaft, edited by H. Bruhns (2013) p. 75 .

12. E.-D. Schulze, J.G. Canadell, EPJ Web of Conferences 98, 04003 (2015). 